\title{
Nucleation and crystallization in bio-based immiscible polyester blends
}

\author{
Seif Eddine Fenni1 ${ }^{1,2}$, Dario Cavallo ${ }^{2 *}$ and Alejandro J. Müller ${ }^{3-4^{*}}$ \\ ${ }^{1}$ Laboratory of Physical-Chemistry of High Polymers (LPCHP), Process Engineering \\ Department, Faculty of Technology, University of Ferhat ABBAS Sétif-1, 19000 Sétif, \\ Algeria \\ ${ }^{2}$ Department of Chemistry and Industrial Chemistry, University of Genova, via Dodecaneso, \\ 31 - 16146 Genova, Italy \\ ${ }^{3}$ POLYMAT and Polymer Science and Technology Department, Faculty of Chemistry, \\ University of the Basque Country UPV/EHU, Paseo Manuel de Lardizabal 3, 20018 \\ Donostia-San Sebastián, Spain \\ ${ }^{4}$ Ikerbasque, Basque Foundation for Science, Bilbao, Spain
}

*Corresponding authors: dario.cavallo@ unige.it and alejandrojesus.muller@ehu.es 


\section{Content}

1. Introduction on immiscible blends of semicrystalline polymers

1.1 Morphological features

1.2 Crystallization behavior in immiscible blends

1.2.1 Fractionated crystallization

1.2.2 Nucleation at polymer/polymer interfaces

1.2.3 Crystallization in presence of compatibilizer and nanoparticles

2 Crystallization in different immiscible biobased polyester blends

2.1 Poly(lactic acid)/poly(butylene succinate) blends

2.2 Poly(lactic acid)/poly( $\varepsilon$-caprolactone) blends

2.3 Poly(butylene succinate)/poly( $\varepsilon$-caprolactone) blends

2.4 Blends of poly(hydroxybutyrate) and other biobased polyesters

3 Conclusions and outlook

\section{List of abbreviations}

\section{Abbreviation}

PLA

Poly (lactic acid)

PLLA

Poly (L-lactic acid)

PDLA

Poly (D-lactic acid)

PBS

poly (butylene succinate)

PCL

poly (caprolactone) or poly ( $\epsilon$-caprolactone)

PHB

Poly (hydroxybutyrate)

TEM

Transmission electron microscopy

PE

Polyethylene

PA

Polyamide

PA6

Polyamide- 6

MDs

Micro domains

DSC

Differential scanning calorimetry

PS

Polystyrene

iPP

Isotactic Polypropylene

PLOM

Polarized Light Microscopy

PVDF

Poly(vinylidene fluoride)

PMMA

Poly(methyl methacrylate)

LDPE

Low density polyethylene 


\begin{tabular}{|c|c|}
\hline DCP & Dicumyl peroxide \\
\hline NPs & Nanoparticles \\
\hline GO & Graphene oxide \\
\hline GOs & Graphene oxide nanosheets \\
\hline $\mathrm{CNC}$ & Cellulose nanocrystals \\
\hline $\mathrm{Tg}$ & Glass transition temperature \\
\hline $\mathrm{wt} \%$ & Weight percentage \\
\hline Tcc & Cold crystallization temperature \\
\hline Tc & Crystallization temperature \\
\hline $\mathrm{Tm}$ & Melting temperature \\
\hline $\mathrm{Xc}$ & Crystallinity degree \\
\hline rPBSL & Random poly(butylene succinate-co-lactic acid) \\
\hline XRD & X-ray diffraction \\
\hline PLLA-g-MA & Maleic-anhydride-grafted PLLA \\
\hline PBS-g-MA & Maleic-anhydride-grafted PBS \\
\hline NPCC & Nano-sized calcium carbonate \\
\hline SB & sodium benzoate \\
\hline $\mathrm{TiO}_{2}$ & Titanium dioxide \\
\hline WAXD & Wide angle $\mathrm{X}$-ray diffraction \\
\hline PBS-g-CNC & PBS-g-cellulose nanocrystal \\
\hline $\mathrm{s}-\mathrm{CNC}$ & Surfactant modified cellulose nanocrystals \\
\hline PBSL & Poly(butylene succinate-co-l-lactate) \\
\hline PEG-PPG & $\begin{array}{l}\text { block copolymer of poly(ethylene glycol) and poly(propylene } \\
\text { glycol }\end{array}$ \\
\hline PLA-b-PC & Poly(L-lactide-block-carbonate) \\
\hline P(LA-ran-CL)LMw & Poly(lactide-ran-caprolactone) Low molecular weight \\
\hline $\mathrm{P}(\mathrm{LA}-\mathrm{ran}-\mathrm{CL}) \mathrm{HMw}$ & Poly(lactide-ran-caprolactone) High molecular weight \\
\hline PLLA-PCL-PLLA & Triblock PLLA-PCL-PLLA copolymer \\
\hline EC-bp & Ethyl cellosolve blocked polyisocyanate \\
\hline POSS & Ad hoc functionalized polyhedral oligomeric silsesquioxane \\
\hline POSS-oib & Octaisobutyl polyhedral oligomeric silsesquioxane \\
\hline GNP & Graphite nanoplatelets \\
\hline LDI & L-lysine-diisocyanate \\
\hline
\end{tabular}


G

Ta

FTIR

PHBV

ATBC

LIM

Lapol

$\tau(50 \%)$
Growth rate

Annealing temperature

Fourier-transform infrared spectroscopy

Poly(hydroxybutyrate-cohydroxyvalerate)

Acetyl(tributyl citrate)

D-limonene

polyester plasticizer

Crystallization half time

\begin{abstract}
Bio-based thermoplastic polyesters are highly promising materials as they combine interesting thermal and physical properties and in many cases biodegradability. However, sometimes the best property balance can only be achieved by blending in order to improve barrier properties, biodegradability or mechanical properties. Nucleation, crystallization and morphology are key factors that can dominate all these properties in crystallizable biobased polyesters. Therefore, their understanding, prediction and tailoring is essential. In this work, after a brief introduction about immiscible polymer blends, we summarize the crystallization behavior of the most important bio-based (and immiscible) polyester blends, considering examples of double-crystalline components. Even though in some specific blends (e.g., polylactide/polycaprolactone) many efforts have been made to understand the influence of blending on the nucleation, crystallization and morphology of the parent components, there are still many points that have yet to be understood. In the case of other immiscible polyester blends systems, the literature is scarce, opening up opportunities in this environmentally important research topic.
\end{abstract}

Keywords: Biobased polyesters, immiscible blends, nucleation, crystallization, double crystalline blends 


\section{Introduction on immiscible blends of semicrystalline polymers}

Recently, much attention has been given to polyesters obtained from sustainable resources, biodegradable polymers and their blends as their properties are comparable with those of polymers derived from petroleum resources but they are more environmentally benign. Among these bio-based and biodegradable polymers, Poly (lactic acid) (PLA), poly (butylene succinate) (PBS), poly (caprolactone) (PCL) and Poly (hydroxybutyrate) (PHB), are the most studied and employed.

Polymer blending has been extensively used to prepare new polymeric materials with an attractive combination of properties that combine those of the pure components. However, given that most polymers are immiscible, because of their unfavorable enthalpy of mixing, they form phase-separated systems. Depending on interfacial tension, composition, rheological properties and processing conditions, immiscible polymer blends exhibit different morphologies, such as sea-island or co-continuous. Immiscible blends are characterized by poor mechanical properties coming from weak interfacial adhesion between the phases and/or stress concentrations at interface boundaries. [1-4] Several strategies have been employed to overcome this and improve blend compatibility, such as chemical modifications, addition of block copolymers, plasticizers, nanofillers and reactive blending [5-7].

If one or both components are semi-crystalline, the superstructure and the crystallization behavior of each material may be affected by blending. The detailed knowledge of how blending impacts crystallization is important since most polymer properties, such as optical, thermal, mechanical and barrier properties, will also be affected.

This chapter describes the general crystallization behavior of immiscible biodegradable polyester blends, with especial emphasis on the kinetics aspects. Several other aspects will also be highlighted, such as the influence of blending on nucleation, the phenomenon of fractionated crystallization, and the effects of composition on the morphology.

\subsection{Morphological features}

The final morphology of immiscible blends is affected both by intrinsic features of the materials, such as interfacial tension between the two polymers and melt viscosity ratio, and by preparation method, i.e., shear rate and blend composition. The two most typical morphologies are: i) droplets of the minor component, with sizes between 0.1 and $10 \mu \mathrm{m}$, 
dispersed in a continuous matrix of the other polymer (i.e., a sea-island morphology), and ii) co-continuous morphology, usually obtained for symmetric compositions, characterized by two continuous phases with similar characteristic sizes that are strongly interpenetrated [1-4]. Co-continuous morphologies in immiscible polymer blends have many advantages in comparison with sea-island morphologies, in particular regarding synergy in the mechanical properties and selective permeability, which provide opportunities for a wide range of technological applications.

Clear relationships have been found between blend morphology and the crystallization of immiscible polymers [8-13]. We have selected an example from the literature, even if the reported blends are not biobased or biodegradable, because it can clearly illustrate the large changes produced by different morphologies on the nucleation and crystallization of the phases.
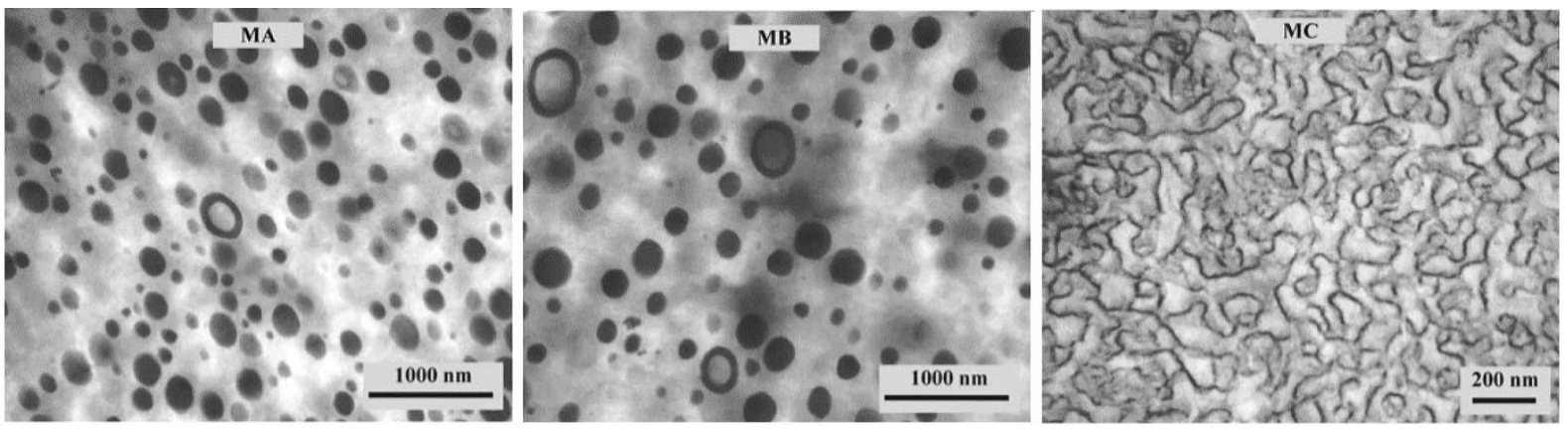

Figure 1. TEM micrographs of three PE/PA blends prepared by reactive extrusion, showing sea-island (MA and MB) and co-continuous morphologies (MC). Adapted from [9].

Figure 1 shows Transmission electron microscopy (TEM) images of polyethylene/polyamide (PE/PA) blends prepared by reactive extrusion. Depending on the composition and compatibilizer content, it was possible to produce two types of morphologies: (i) droplets of polyamide in a polyethylene matrix (samples MA and MB in Figure 1), (ii) co-continuous morphology of the two polymers (sample MC, Figure 1) [9]. The kinetics of crystallization of PA in PE/PA immiscible blends changed from classical sigmoidal-type (typical of heterogeneously nucleated polymers with Avrami indexes of 3-4), in the blend with the co-continuous morphology, to first-order kinetics in the blends MA with sea-island morphology with sub-micron PA droplets (typical of a crystallization process initiated by surface nucleation or homogeneous nucleation $[8,9,12])$. In the MC blend, the nucleation was found to be heterogeneous at lower supercooling, while in MA and MB blends, the nucleation became homogeneous or induced by the polymer-polymer interface, 
and crystallization occurred at extremely large supercooling. On the other hand, crystallization of the PE phase was enhanced in all blends, due to the nucleation effect of the PA, previously crystallized at higher temperature [9]. The relationship between immiscible blend morphology and crystallization behavior of bio-based polyester blends will be analyzed in detail below.

\subsection{Crystallization behavior in immiscible blends}

The polymers in an immiscible blend can be either amorphous or semicrystalline. Thus, amorphous/amorphous, crystalline/amorphous or crystalline/crystalline final blends can be prepared.

In principle, phase separation of the components is expected, therefore, in the case of two semicrystalline components, the crystallization of each polymer takes place independently from one another. As such, the crystalline features (melting temperature $(\mathrm{Tm})$, lamellar thickness, and growth rate $(G)$ ) are expected to be similar to the ones of pure components . The same does not obviously hold for miscible blends, where dilution effects on crystallization can be appreciated. $[10,11,13]$.

However, the crystallization kinetics of a given polymer in an immiscible blend can be substantially different from that of the pure component, since peculiar nucleation effects can arise. Nucleation could be enhanced and thus the overall crystallization kinetics is accelerated. Indeed, nucleation is commonly encountered at foreign surfaces, and it can thus be increased due to impurities/heterogeneities migration between the different phases during the blending process or to the presence of polymer/polymer interfaces. [1,2,10,13-17]. The opposite situation, i.e., a decrease of crystallization kinetics, is also commonly observed whenever the crystallizable polymers are separated in a "sufficiently high" number of individual domains. In these cases, the phenomenon is addressed as fractionated crystallization, as detailed in the following section.

\subsubsection{Fractionated crystallization}

The term "fractionated crystallization" was introduced by Frensch et al. [18]. This crystallization mechanism is observed in polymer blends, when a minor crystallizable component is dispersed in droplets with very small average diameter. The fractionated crystallization appears when the number of droplets or micro domains (MDs) is of the same order of magnitude, or larger, than the number of the active heterogeneities which act as 
primary nuclei for crystallization in the bulk polymer. For statistical reasons, different droplets ensembles will result, containing heterogeneities with varying nucleating ability, or even free of foreign particles. Therefore, upon cooling from the melt, the different fractions of droplets will crystallize at distinct supercoolings, from low to high depending on the nucleating efficiency of the contained heterogeneities. Ideally, "clean" droplets will solidify at the maximum achievable supercooling (close to the glass transition temperature) by a homogeneous nucleation mechanism. Heterogeneity free droplets can also crystallize by interfacial nucleation at high supercoolings, but not as high as in the case of homogeneous nucleation, since the energy barrier for nucleation is lower when the interface between the two phases is able to nucleate the droplets. The different nucleation events are reflected in multiple exothermic peaks detected by a differential scanning calorimetry (DSC) cooling scan [10,12,13, 19-29].

The above outlined concept is described schematically in Figure 2. The most active nucleating impurities are represented with the letter A, while B indicated less active heterogeneities. After blending, the heterogeneities will be randomly distributed among the droplets. The micro domains containing type A heterogeneities crystallize at lower supercooling (exothermic peak 1 in the DSC of Figure 2), while droplets with type B impurities nucleate at lower temperatures (DSC peak 2). Impurities-free polymer droplets reach the largest supercooling for the given cooling conditions (exothermic peak 3).

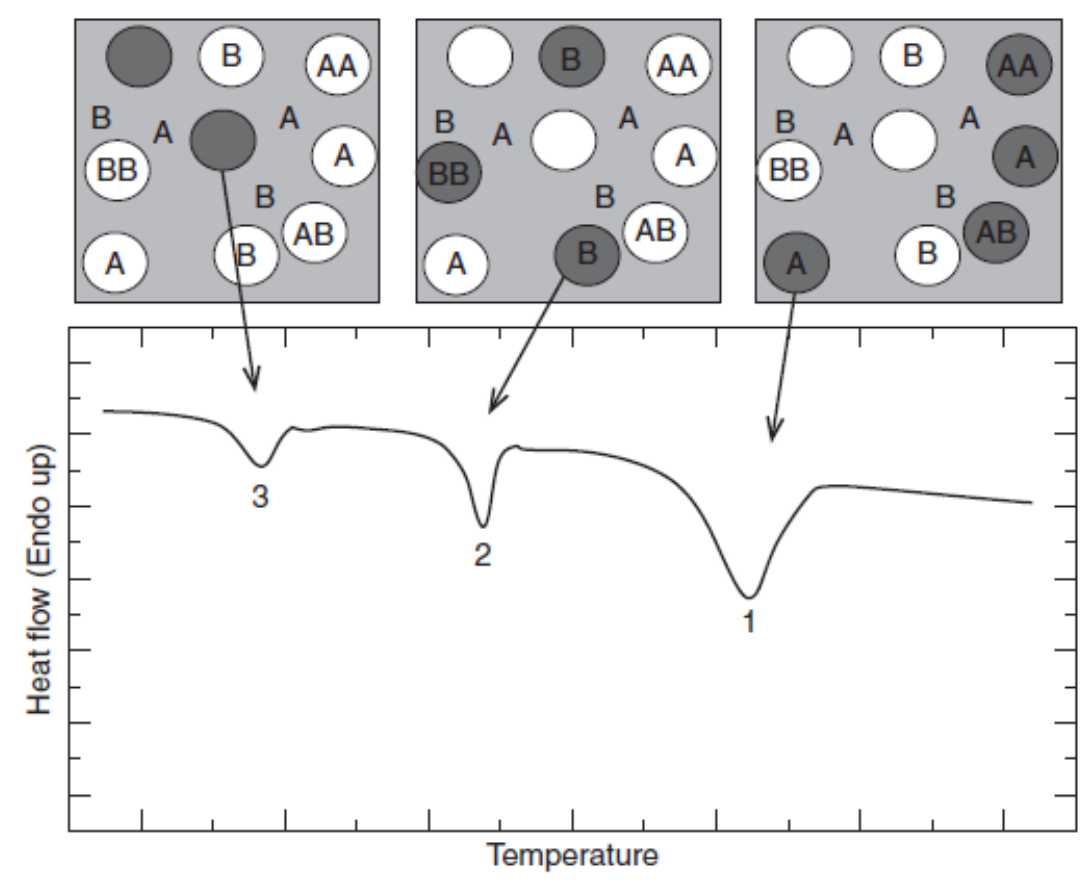


Figure 2: A schematic illustration of the fractionated crystallization of polymer droplets dispersed in an immiscible polymer matrix, as measured by DSC [19].

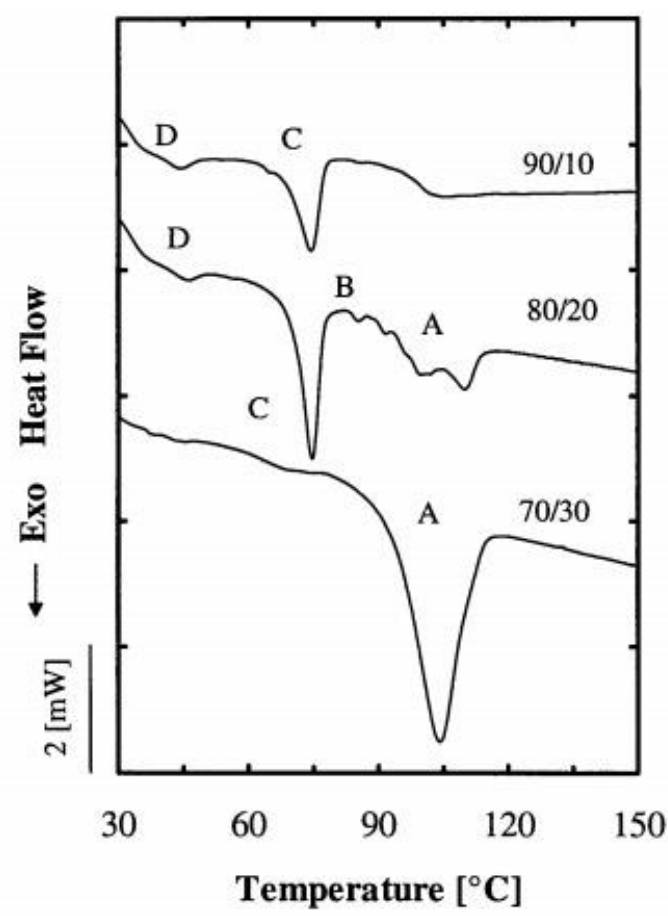

Figure 3. DSC cooling curves at $10^{\circ} \mathrm{C} / \mathrm{min}$ for $\mathrm{PS} / \mathrm{iPP}$ blends with the indicated compositions. [21].

Figure 3 shows a real example of fractionated crystallization in immiscible blends, and the effect of blend composition on its occurrence, for the system isotactic polypropylene/polystyrene. For a 70/30 wt\% composition, isotactic Polypropylene (iPP) droplets have an average diameter of 7-9 $\mu \mathrm{m}$ and they mostly crystallize at low supercooling (peak A) while a small fraction of the droplets can be supercooled to a larger extent (peak C). By decreasing the amount of iPP to $20 \%$, the average droplet size decreases to around 1-2 $\mu \mathrm{m}$, and a clear fractionated crystallization is observed: since four distinct crystallization exotherms (A-D) are revealed. These correspond to different types of heterogeneities (A-C) and to nucleation at the interface with polystyrene (PS) or via a homogenous route in pure iPP droplets (D). When iPP content is only $10 \mathrm{wt} \%$, the average droplets size is less than $1 \mu \mathrm{m}$. The concentration of droplets thus increases well above the content of the heterogeneities which cause nucleation at low supercoolings (peaks A through $\mathrm{C}$ ). In fact, the high temperatures nucleation events (A and B) disappear and the crystallization can only occur at lower temperatures, in exotherms $\mathrm{C}$ and D. If a compatibilizer is used in the blend, even smaller droplets are produced and exotherm C disappears, indicating that the only event associated with heterogeneity free droplets is the exothermic peak at maximum supercooling 
(D) which could be started by surface nucleation or homogeneous nucleation. As the glass transition temperature (Tg) temperature of iPP is close to $0{ }^{\circ} \mathrm{C}$ and the crystallization peak (D) is at around $40{ }^{\circ} \mathrm{C}$, it may be possible that a homogeneous nucleation process could have triggered the nucleation of these clean droplets. $[8,10,12,21,23,24]$ In general, the fractionated crystallization leads to lower crystallinity and slightly lower melting temperatures, due to the decrease of lamellar thickness at those supercoolings [8,11,13,26,27]. For more details on fractionated crystallization, the reader is referred to the reviews of Müller et al. [12,21,25]

\subsubsection{Nucleation at polymer/polymer interfaces}

Several papers have reported the nucleation effect of one polymer on another in immiscible blends. The phenomenon is commonly indicated as interface-induced nucleation or interface-assisted crystallization, and can be typically visualized directly by Polarized Light Microscopy PLOM [30-37].

For example, Figure 4 shows some PLOM micrographs of the area near the phase boundary between poly(L-lactide) (PLLA) and poly(vinylidene fluoride) (PVDF). The two polymers were sequentially crystallized for a suitable time at $150{ }^{\circ} \mathrm{C}$ and $140{ }^{\circ} \mathrm{C}$. At $150^{\circ} \mathrm{C}$, only the PVDF phase is able to crystallize within the given time (Figure 4b), while after cooling to $140^{\circ} \mathrm{C}$, PLLA can also crystallize. At $140^{\circ} \mathrm{C}$, PLLA nucleates first at the interface with previously crystallized PVDF. A transcrystalline structure is produced due to the high (linear) nucleation density, which forces the spherulites to grow perpendicular to the interface (Figures $4 \mathrm{c}$ and $4 \mathrm{~d}$ ). We can note that, during the same crystallization time, only few PLLA spherulite nucleate within the bulk phase, away from the PVDF interface [33].

In a similar experiment on PVDF/PCL blends, the nucleation of the PCL phase after isothermal crystallization of PVDF was shown to occur at the interface with PVDF crystals, giving rise again to a transcrystalline PCL layer. The nucleation effect of PVDF on PCL could also be detected by non-isothermal differential scanning calorimetry, as a meaningful shift of PCL crystallization exotherm to higher temperature in a 70/30 wt\% PVDF/PCL blend [34].

The nucleation of a given polymer on the surface of pre-existing crystals of a different polymer might not seem surprising, and can be possibly attributed to the existence of epitaxial relationship between the two crystalline structures. However, even if less documented, the nucleation of a semicrystalline polymer at the interface with an amorphous polymer in their immiscible blend is also possible. Figure 5 shows a polarized optical micrographs of isotactic polypropylene/poly(methyl methacrylate) (PP/PMMA) immiscible blend crystallized at $130^{\circ} \mathrm{C}$. iPP transcrystalline growth layer around the PMMA domains can be observed. It 
should be noted that iPP crystallization takes place above the glass transition temperature of PMMA, thus the nucleation effectively occurs at the interface with a viscous liquid [35].

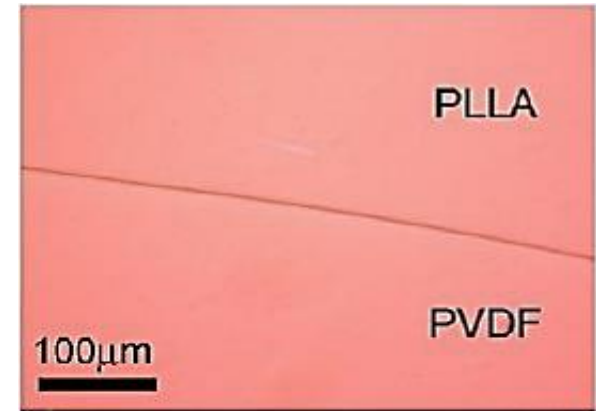

a) $150^{\circ} \mathrm{C}, 0 \mathrm{~min}$

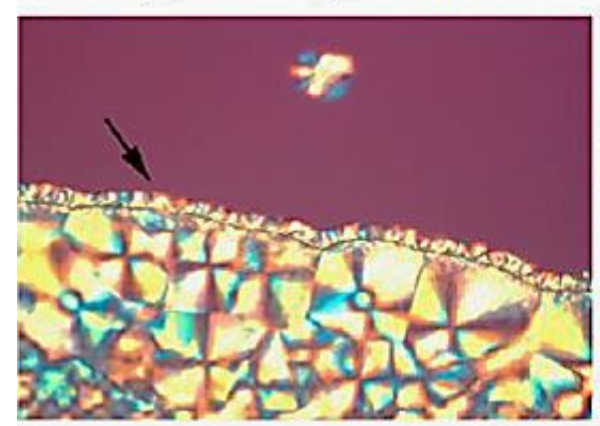

c) $140^{\circ} \mathrm{C}, 10 \mathrm{~min}$

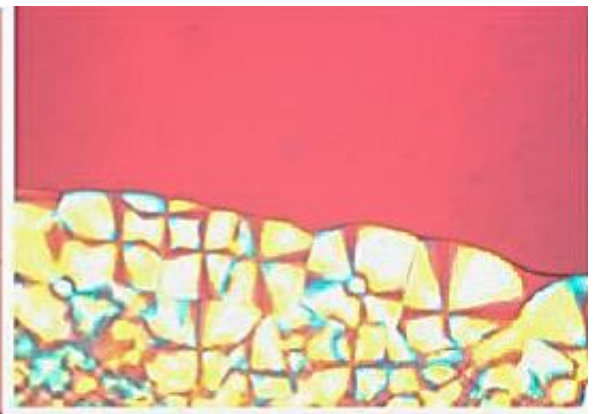

b) $150{ }^{\circ} \mathrm{C}, 6 \mathrm{~min}$

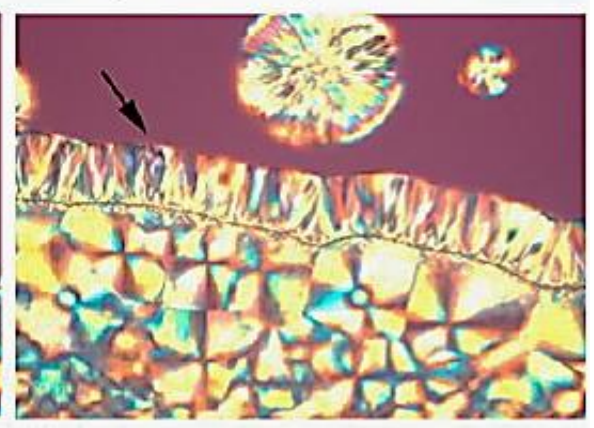

d) $140^{\circ} \mathrm{C}, 30 \mathrm{~min}$

Figure 4: PLOM micrographs of PLLA and PVDF near their interface, during a sequential crystallization at 150 and $140{ }^{\circ} \mathrm{C}$. The upper and lower sides of the micrographs are PLLA and PVDF, respectively. Adapted from ref. [33].

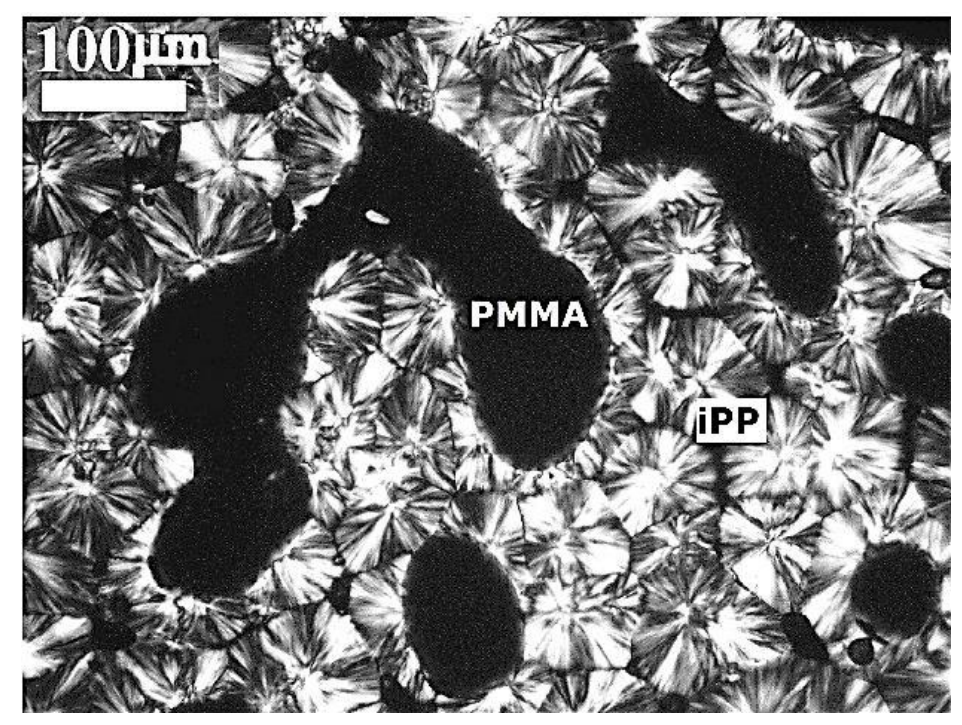

Figure 5: PLOM micrograph for an iPP/PMMA blend after the sample was crystallized at $130{ }^{\circ} \mathrm{C}$ for $30 \mathrm{~min}$. Adapted from reference [35]. 


\subsubsection{Crystallization in presence of compatibilizers and nanoparticles}

Usually, the addition of small amounts of "compatibilizer" (i.e., block-copolymers, graft copolymers, nanoparticles, etc.) results in large decrease in the size of the dispersed phase, in comparison with the non-compatibilized blend. The addition of a copolymer-based compatibilizer, in general, has remarkable influence on the crystallization behavior of the blend components, because of the large effect on the morphology of the system, which results either in a decrease in the size of the dispersed phase or in the formation of a percolated/cocontinuous morphology [8,13,16,38,39]. Tol et al. [26], Yordanov and Minkova [28], studied the reactive compatibilization of the immiscible blends polystyrene/polyamide 6 (PS/PA6) and Low density polyethylene/polystyrene (LDPE/PS), using different kind of copolymer compatibilizers. They found a decrease in the droplet sizes and large increase in the droplets concentration. As a consequence, the nucleation mechanism of the crystalline polymer changed from heterogeneous to homogeneous/surface-induced. In the case of PA6, the increased supercooling favored the crystalline $\gamma$ phase with respect to the $\alpha$ phase which develops in neat blends [26].

Another commonly used compatibilization method is "reactive blending", in which a molecule which can react with one or both phases is added during the extrusion process. During the reactive compatibilization, different kind of interactions among the polymers can develop, leading to hydrogen, ionic, or covalent bonding, depending on the specific functional groups involved. Typically, a co-continuous morphology can be obtained. In the case of reactive compatibilization, when some specific reagent is employed, the crystallization behavior of the final blend can be affected as a result of chain scission or reduction of chain mobility due to cross-linking. In general, reactive compatibilization reduces the degree of crystallinity and induces fractionated crystallization [1,2,5,11,13,21,27,28, 39-42].

Wang et al. [41] reported that the addition of dicumyl peroxide (DCP) at different concentrations to PLA/PBS 80/20 immiscible blend hinders the crystallization of both components, i.e., it decreases the crystallinity of both PBS and PLA and the cold crystallization rate of PLA by reducing its nucleation density. Reactive blending in this case is creating new covalent bonds randomly distributed in between the two polymers. Such new covalent bonds interrupt the linear crystallizable sequences creating molecular defects that need to be rejected to the amorphous phases, thereby reducing the crystallization ability of the components. 
The addition of nanoparticles (NPs) or nanofillers to immiscible polymer blends can have an effect on the mechanical, thermal, optical and gas properties. NPs in immiscible blends could be located at the interface between the components, dispersed preferentially in one component, or dispersed in non-equivalent way in both components. Generally, and depending on their locations, NPs affect the crystallization behavior of the crystallizable components by enhancing the primary nucleation, thus acting as heterogeneous nucleants. [13, 43-45]. Examples can be found for instance for PLLA/PBS blends mixed with graphene oxide (GO) and cellulose nanocrystals (CNC) [44,45].

\section{Crystallization in different immiscible bio-based polyester blends}

\subsection{Poly (lactic acid) / poly (butylene succinate) blends}

This section presents a short review on previous research about PLA/PBS blends in which the effect of addition of PBS on different properties of the PLA matrix is studied with the aim of improving mechanical properties, gas barrier behavior etc. PLA is a biobased polyester that has high rigidity, biocompatibility and biodegradability. However, it presents slow crystallization and brittleness. PBS on the other hand, is a biodegradable polyester with good processability. The commonly observed thermal transitions of the two materials are summarized in the following. PLA partially crystallizes on cooling around $100^{\circ} \mathrm{C}$ and vitrifies at the glass transition temperature $\left(\mathrm{Tg} \approx 60^{\circ} \mathrm{C}\right)$. Upon subsequent heating it might show cold crystallization above $\mathrm{Tg}$ (typically at $\approx 100^{\circ} \mathrm{C}$ ) and melting with a peak temperature of $\approx 170^{\circ} \mathrm{C}$. On the other hand PBS crystallizes on cooling at $\approx 75^{\circ} \mathrm{C}$, has a low glass transition temperature $\left(\approx-35^{\circ} \mathrm{C}\right)$ and melts slightly above $116{ }^{\circ} \mathrm{C}$. We recall that for PLA the crystallization and melting temperatures are controlled by the relative contents of D- and Lisomer of lactide in the chain [46-48].

Several authors investigated the effect of cooling and heating rates, blend composition and addition of compatibilizers, nanoparticles and nucleating agents on the thermal and crystallization behavior of PLA/PBS blends [15,41,45,49-56]. Both non-isothermal with varying cooling rates and isothermal crystallization behavior were investigated, using differential scanning calorimetry (DSC) and polarized optical microscopy (PLOM). The main works performed on PLA/PBS based systems are schematically summarized in Table 1. 
Table 1. Reported experimental works on PLA/PBS based blends, with emphasis on the aspects related to nucleation and crystallization.

\begin{tabular}{|c|c|c|c|c|c|c|c|c|}
\hline Sample & $\begin{array}{c}\text { Publication } \\
\text { year }\end{array}$ & $\begin{array}{l}\text { Composition } \\
\text { wt } \%\end{array}$ & $\begin{array}{l}\text { Crystallization } \\
\text { /nucleation } \\
\text { conditions and } \\
\text { technics } \\
\end{array}$ & $\begin{array}{l}\text { Tcc } \\
\text { of } \\
\text { PLA } \\
\left({ }^{\circ} \mathrm{C}\right)\end{array}$ & $\begin{array}{l}T c \text { of } \\
\text { PLA } \\
\left({ }^{\circ} \mathrm{C}\right)\end{array}$ & $\begin{array}{l}T c \text { of } \\
\mathrm{PBS} \\
\left({ }^{\circ} \mathrm{C}\right)\end{array}$ & $\begin{array}{c}\text { Crystallization/nucleation } \\
\text { outcomes }\end{array}$ & $\begin{array}{l}\text { Ref } \\
\text { eren } \\
\text { ce }\end{array}$ \\
\hline \multirow[t]{4}{*}{ PLLA/PBS } & \multirow[t]{4}{*}{2006} & Neat PLLA & \multirow{4}{*}{$\begin{array}{l}\text { Isothermal and } \\
\text { non-isothermal } \\
\text { DSC at various } \\
\text { cooling rates. }\end{array}$} & 124.0 & - & - & \multirow{4}{*}{$\begin{array}{l}\text { PBS accelerates the cold } \\
\text { crystallization of PLA, but is less } \\
\text { effective in melt crystallization. } \\
X c \text { increases with PBS content. }\end{array}$} & \multirow[t]{4}{*}{51} \\
\hline & & $99 / 1$ & & 113.3 & - & - & & \\
\hline & & $95 / 5$ & & 96.7 & - & - & & \\
\hline & & $90 / 10$ & & 94.8 & - & - & & \\
\hline \multirow{4}{*}{$\begin{array}{l}\text { PLLA/ } \\
\text { PBSL }\end{array}$} & \multirow[t]{4}{*}{2006} & Neat PLLA & \multirow{4}{*}{$\begin{array}{l}\text { Non-isothermal } \\
\text { DSC at various } \\
\text { cooling rates; } \\
\text { Isothermal DSC }\end{array}$} & 124.0 & - & - & \multirow{4}{*}{$\begin{array}{l}\text { Molten PBSL enhances the isothermal } \\
\text { and non-isothermal PLLA } \\
\text { crystallization during the cooling } \\
\text { process and accelerates Tcc during the } \\
\text { heating process. } X c \text { was found to } \\
\text { increase with the addition of PBSL. }\end{array}$} & \multirow[t]{4}{*}{51} \\
\hline & & $99 / 1$ & & 102 & - & - & & \\
\hline & & $95 / 5$ & & 90.2 & - & - & & \\
\hline & & $90 / 10$ & & 95.6 & - & - & & \\
\hline PLA/PBS & 2008 & $\begin{array}{l}0-20 \text { wt } \% \text { of } \\
\text { PBS. }\end{array}$ & $\begin{array}{l}\text { DSC and PLOM : } \\
\text { cooling from } \\
180^{\circ} \mathrm{C} \text { at } 2^{\circ} \mathrm{C} / \mathrm{min} \text {. }\end{array}$ & - & - & - & $\begin{array}{l}\text { Addition of PBS accelerates the } \\
\text { crystallization rate of PLA during } \\
\text { both cooling and heating scans and } \\
\text { the PBS domains act as nuclei for } \\
\text { PLA. }\end{array}$ & 49 \\
\hline \multirow{6}{*}{$\begin{array}{l}\text { PLA/PBS/ } \\
\text { DCP }\end{array}$} & \multirow[t]{6}{*}{2009} & Neat PLA & \multirow{6}{*}{$\begin{array}{l}\text { DSC non- } \\
\text { isothermal } \\
\text { crystallization } \\
\text { PLOM isothermal } \\
\text { crystallization } \\
\text { X-Ray Diffraction }\end{array}$} & 122.4 & - & - & \multirow{6}{*}{$\begin{array}{l}\text { The addition of PBS accelerates the } \\
\text { cold crystallization of PLA, while } \\
\text { addition of DCP hinders both PLA } \\
\text { and PBS crystallization. PBS acts as a } \\
\text { nucleating agent for PLA but the } \\
\text { effect is reduced after reaction with } \\
\text { DCP. }\end{array}$} & \multirow[t]{6}{*}{41} \\
\hline & & $80 / 20$ & & - & - & - & & \\
\hline & & $80 / 20 / 0.05$ & & - & - & - & & \\
\hline & & $80 / 20 / 0.1$ & & 120.1 & - & - & & \\
\hline & & $80 / 20 / 0.15$ & & 122.6 & - & - & & \\
\hline & & $80 / 20 / 0.2$ & & 124.2 & - & - & & \\
\hline \multirow[t]{4}{*}{ PLLA/PBS } & \multirow[t]{4}{*}{2012} & Neat PLLA & \multirow{4}{*}{$\begin{array}{l}\text { DSC non- } \\
\text { isothermal } \\
\text { crystallization }\end{array}$} & 132.5 & - & - & \multirow{4}{*}{$\begin{array}{l}\text { Presence of PBS accelerates } \\
\text { remarkably the cold crystallization of } \\
\text { PLA, but no effect was recorded } \\
\text { during the cooling process from the } \\
\text { melt. } \\
\text { PLA domains does not affect the } \\
\text { crystallization behavior of PBS. }\end{array}$} & \multirow[t]{4}{*}{52} \\
\hline & & Neat PBS & & 116.2 & - & 83.8 & & \\
\hline & & $50 / 50$ & & - & - & 84.4 & & \\
\hline & & $20 / 80$ & & - & - & 84.7 & & \\
\hline $\begin{array}{l}\text { PLA/PBS/P } \\
\text { LLA- } g \text {-MA } \\
\text { And } \\
\text { PLA/PBS/P } \\
\text { BS- } g \text {-MA }\end{array}$ & 2014 & $\begin{array}{l}0-100 \mathrm{wt} \% \\
\text { of PBS. } \\
\text { With 0-4 } \\
\text { wt } \% \text { of } \\
\text { PLLA-g-MA } \\
\text { or PBS-g- } \\
\text { MA }\end{array}$ & $\begin{array}{l}\text { Non-isothermal } \\
\text { DSC }\end{array}$ & - & - & - & $\begin{array}{l}\text { PBS enhances the cold crystallization } \\
\text { of PLA. The size and number of the } \\
\text { dispersed PBS particles (droplets) has } \\
\text { a significant influence on the } \\
\text { crystallization rate of PLA (the } \\
\text { smallest and highest number of } \\
\text { dispersed PBS droplets resulted in } \\
\text { higher nucleation effect). Addition of } \\
\text { compatibilizer produced additional } \\
\text { increases in the crystallinity of the } \\
\text { blend. }\end{array}$ & 53 \\
\hline \multirow{5}{*}{$\begin{array}{l}\mathrm{PLA} / \mathrm{PBS} / \\
\mathrm{TiO} 2 \\
\text { nanoparticl } \\
\text { es }\end{array}$} & \multirow[t]{5}{*}{2014} & $90 / 10$ & \multirow{5}{*}{$\begin{array}{l}\text { Non-isothermal } \\
\text { DSC }\end{array}$} & 95.7 & - & - & \multirow{5}{*}{$\begin{array}{l}\text { DSC analysis showed that addition of } \\
\mathrm{TiO}_{2} \text { promoted the crystallization of } \\
\text { PLA. PBS has lower nucleating effect } \\
\text { as compared with } \mathrm{TiO}_{2} \text {. }\end{array}$} & \multirow[t]{5}{*}{54} \\
\hline & & $90 / 10 / 1$ & & 96.8 & - & - & & \\
\hline & & $90 / 10 / 2$ & & 98.4 & - & - & & \\
\hline & & $90 / 10 / 3$ & & 107.9 & - & - & & \\
\hline & & $90 / 10 / 5$ & & 94.7 & - & - & & \\
\hline PLA/PBS & 2015 & $\begin{array}{l}0-100 \mathrm{wt} \% \\
\text { of PBS }\end{array}$ & $\begin{array}{l}\text { DSC and PLOM } \\
\text { non-isothermal } \\
\text { crystallization at a } \\
\text { scan rate of } \\
10^{\circ} \mathrm{C} / \mathrm{min} \text {. }\end{array}$ & - & - & - & $\begin{array}{l}\text { After blending, crystallinity of both } \\
\text { PLA and PBS increased. } \\
\text { Addition of } 20 \mathrm{wt} \% \text { of PBS gave the } \\
\text { largest increase in the crystallinity of } \\
\text { PLA }\end{array}$ & 15 \\
\hline $\begin{array}{l}\text { PLA/PBS/ } \\
\text { rPBSL }\end{array}$ & 2016 & $\begin{array}{l}80 / 20 \mathrm{wt} \% \\
\text { with } 0-5 \mathrm{phr} \\
\text { of rPBSL }\end{array}$ & $\begin{array}{l}\text { DSC non- } \\
\text { isothermal } \\
\text { crystallization } \\
\text { PLOM isothermal } \\
\text { crystallization at } \\
80^{\circ} \mathrm{C} \text {. }\end{array}$ & - & - & - & $\begin{array}{l}\text { Addition of rPBSL to } 80 / 20 \text { PLA/PBS } \\
\text { blend affects nucleation and } \\
\text { crystallization, since the compound } \\
\text { acts as a nucleating agent and } \\
\text { plasticizer. }\end{array}$ & 50 \\
\hline
\end{tabular}




\begin{tabular}{|c|c|c|c|c|c|c|c|c|}
\hline $\begin{array}{l}\text { PLA/PBS/ } \\
\text { DCP/PBS- } \\
g-\mathrm{CNC}\end{array}$ & 2016 & $\begin{array}{c}\text { 70/70 wt\% } \\
\text { with } \\
\text { DCP/PBS-g- } \\
\text { CNC }=0 / 0 \\
0 / 2,0.2 / 0 \\
0.2 / 0.5 \\
0.2 / 1 \text { and } \\
0.2 / 2 \text {. }\end{array}$ & $\begin{array}{l}\text { Non-isothermal } \\
\text { DSC, WAXD }\end{array}$ & - & - & - & $\begin{array}{l}\text { DCP and PBS- } g \text {-CNC have a strong } \\
\text { contribution to the formation of PLA } \\
\alpha \text { form and low effect on PBS } \\
\text { crystallization. In addition, PBS- } g \text { - } \\
\text { CNC increases the crystallinity degree } \\
\text { of the PLA/PBS system and affects } \\
\text { the crystal size of both PLA and PBS. } \\
\text { Addition of DCP restricts the } \\
\text { crystallization. }\end{array}$ & 55 \\
\hline \multirow{6}{*}{$\begin{array}{l}\text { PLLA/PBS } \\
/ \mathrm{GO}\end{array}$} & \multirow[t]{6}{*}{2018} & Neat PLLA & \multirow{6}{*}{$\begin{array}{l}\text { DSC in isothermal } \\
\text { and non- } \\
\text { isothermal }\end{array}$} & 97 & 101.6 & - & \multirow{6}{*}{$\begin{array}{l}\text { In the neat blend, fractionated } \\
\text { crystallization of PBS phase and slight } \\
\text { increase in Tc of PLLA was observed } \\
\text { Addition of GOs enhance the } \\
\text { crystallization rate of both PLA and } \\
\text { PBS. }\end{array}$} & \multirow[t]{6}{*}{45} \\
\hline & & Neat PBS & & - & - & 77 & & \\
\hline & & $70 / 30$ & & 91 & 105.2 & 73 & & \\
\hline & & $70 / 30 / 0.1$ & & - & 103.7 & 92 & & \\
\hline & & $70 / 30 / 0.3$ & & - & 105.5 & 92 & & \\
\hline & & $70 / 30 / 0.5$ & & - & 105.5 & 92 & & \\
\hline
\end{tabular}

In the case of PLA/PBS blends, the crystallization and melting temperatures of the two polymers in the blends remains in the same range of that of the pure components, confirming the immiscibility between the two polyesters. The melting processes are sufficiently apart to be distinguished upon heating.

The crystallization rate of PLA is rather slow, so that often the structuring process is not completed during cooling, and an exothermic cold-crystallization peak is usually observed during the second heating scan. Several works have reported an acceleration of PLA cold crystallization rate by the addition of PBS [15,41,45,49,51-55]. Figure 6 presents a collection of the reported cold-crystallization temperatures of PLA in its blends with PBS, as a function of PBS content. The data has been normalized by using the difference between the coldcrystallization temperature of neat PLA and of the PLA component in the blend. The more negative the value of $\Delta T_{c c}$ is, the larger the nucleation effect upon heating from the glassy state.

Notwithstanding the differences in the absolute values of cold-crystallization temperatures, which might attributed to material (molar mass, D-lactide content) or measurement (heating rate) parameters, a clear shift of the cold-crystallization events towards lower temperature can be appreciated, especially upon the addition of a minor content of PBS (in the range 1-30 wt\%). The largest nucleation effect can be approximately found for PBS content between 5 and $15 \mathrm{wt} \%$. This is interpreted as the result of a decrease in the PBS droplets diameter, which lead to an increase in the PLA/PBS interfacial area. 


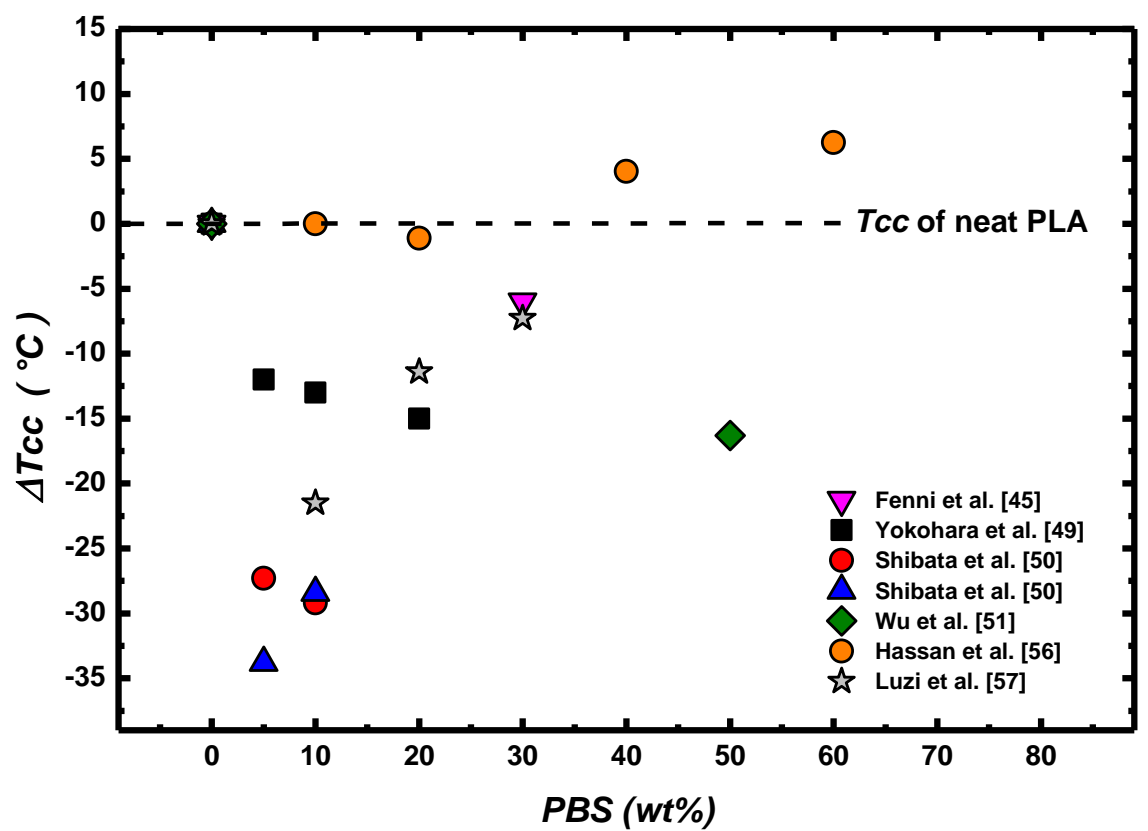

Figure 6: Cold crystallization of PLA as a function of PBS content in different PLA/PBS blends reported in literature.

Although several works attributed this change in cold-crystallization rate to a certain miscibility between PLLA and PBS [50,58] at least on a local scale, this could not be sustained by any meaningful change in the glass transitions or morphology, while the growth rate is mostly unexplored. More probably, the enhancement of PLLA cold-crystallization can be well described as a heterogeneous nucleation phenomenon at the interface between the two polymer phases, thanks to the PBS crystals formed upon cooling. The possibility of impurities transfer between two melts cannot be ruled-out, but is not required to account for the observations.

On the other hand, only a limited number of works reported the effect of molten PBS in nucleating PLA during the cooling process or melt-crystallization [15,45,49,51]. For example, Yokohara and Yamaguchi [49] found that the addition of small amount of PBS largely increases the number of PLA nuclei, as observed by PLOM, and even enables the crystallization of the polymer during cooling at around $90{ }^{\circ} \mathrm{C}$. It should be noted that the melt crystallization of PLA necessarily occurs in a temperature range in which PBS is in the molten state. Therefore, the lower nucleating efficiency of the liquid-liquid contact surface could be expected.

Few studies have paid attention to the effect of the presence of PLA on PBS phase crystallization. Deng and Thomas [15] reported that blending PLA and PBS resulted in an increase in PBS crystallinity degree, which was tentatively attributed to a nucleating effect of 
PLA crystals. Differently, Hassan et al. [57], reported a decrease in the degree of crystallinity of PBS when it constitutes the minority phase in blends with PLA, as a consequence of fractionated crystallization and hindrance to the crystallization process exerted by the solidified PLA matrix. Fenni et al. [45], also reported the appearance of fractionated crystallization of PBS phase and a large slowing down of its crystallization kinetics compared to pure PBS in PLA/PBS 70/30 wt\% immiscible blend.

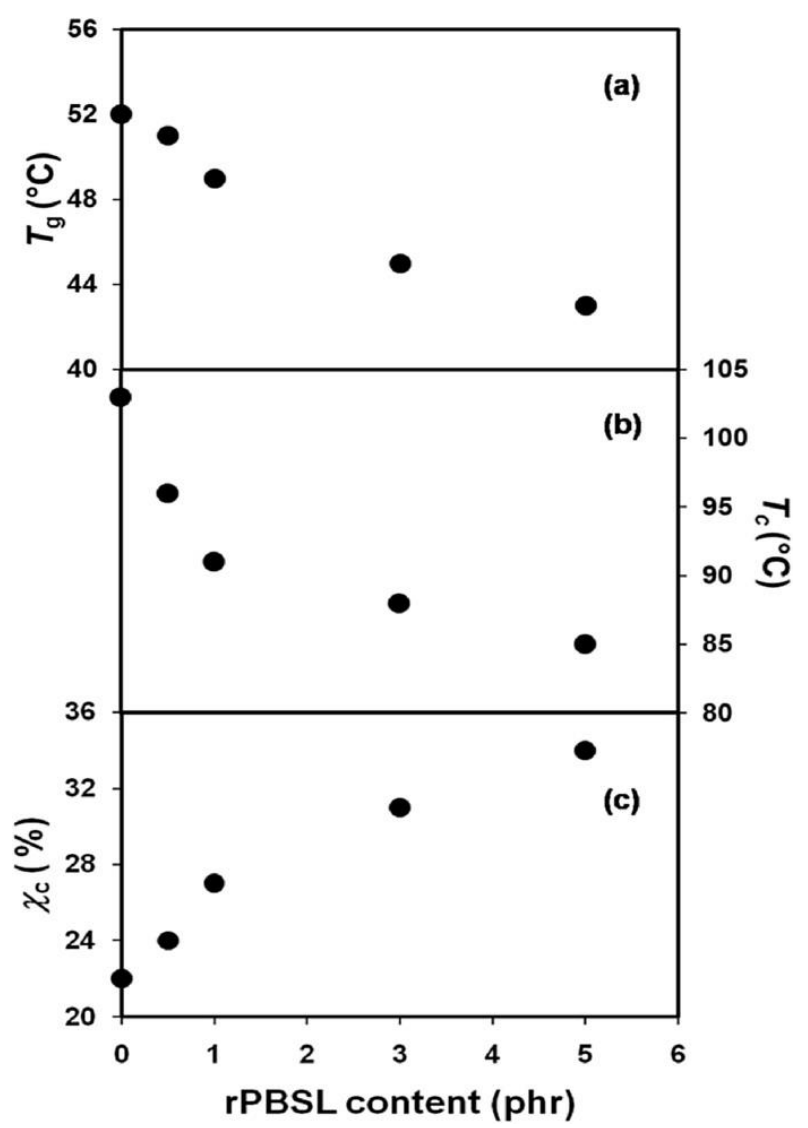

Figure 7: Glass transition (a), cold-crystallization temperature (b) and crystallinity (c) of PLA in PLA/PBS (80/20) blends with different contents of rPBSL [50].

Lastly, the effect of compatibilization, according to different strategies, on PLA/PBS blend crystallization can be analyzed. Wang et al. [41] employed dicumyl peroxide (DCP) with a content of $0-0.2 \mathrm{wt} \%$ to compatibilize an 80/20 wt\% PLA/PBS blend. In the neat blend, PBS acted as nucleating agent for PLA, both during the heating process or during isothermal conditions below its melting point. A reduction in PBS crystallization and PLLA cold crystallization ability with increase of DCP content was observed, and attributed to the increase in the viscosity of system. However, the interruption of crystallizable chain sequences was not considered. Also, the decrease in PBS crystallinity could be related to the 
decrease in domains size with increase of DCP content and the appearance of fractionated crystallization phenomena.

Supthanyakul et al. [50], used a random poly (butylene succinate-ran-lactic acid) (rPBSL) copolymer as compatibilizer between PLA and PBS 80/20 wt\% blends. The random copolymer was partially miscible with PLA, as deduced from the plasticization effect, with the glass transition temperature dropping about $10{ }^{\circ} \mathrm{C}$ for $5 \mathrm{phr}$ of rPBSL (see Figure $7 \mathrm{a}$ ). The enhanced PLA mobility favored cold crystallization, which occurred much earlier on heating and lead to higher crystallinity (Figure $7 \mathrm{~b}$ and $7 \mathrm{c}$ ). The interpretation of the accelerated crystallization to molecular mobility is supported by the measured increased in PLA growth rate, and decrease in spherulite induction time with increasing rPBSL content.

\subsection{Poly (lactic acid) / poly ( $\varepsilon$-caprolactone) blends}

PLA/PCL immiscible blends have been extensively investigated, given the possible attractive combination of properties resulting from the mixture of these two components. PCL is a biodegradable polyester with a very flexible chain, characterized by a low glass transition temperature $\left(\approx-60^{\circ} \mathrm{C}\right)$, although the melting and crystallization also occur in the lowtemperature range at around 60 and $30^{\circ} \mathrm{C}$, respectively. In this section, the main works dealing with the crystallization behavior of these blends, including the effect of composition and additives, are summarized [16,31,32,36,38,59-78]. Table 2 provides a compendium of the related studies.

Table 2. Main experimental works on PLA/PCL based blend, with emphasis on the aspects related to crystallization and nucleation.

\begin{tabular}{|c|c|c|c|c|c|c|c|c|}
\hline Sample & $\begin{array}{c}\text { Publication } \\
\text { year }\end{array}$ & $\begin{array}{l}\text { Composition } \\
\text { wt } \%\end{array}$ & $\begin{array}{l}\text { Crystallization } \\
\text { /nucleation } \\
\text { conditions and } \\
\text { technics }\end{array}$ & $\begin{array}{l}\text { Tcc } \\
\text { of } \\
\text { PLA } \\
\left({ }^{\circ} \mathrm{C}\right)\end{array}$ & $\begin{array}{l}T c \text { of } \\
\text { PLA } \\
\left({ }^{\circ} \mathrm{C}\right)\end{array}$ & $\begin{array}{l}\text { Tc of } \\
\text { PCL } \\
\left({ }^{\circ} \mathrm{C}\right)\end{array}$ & $\begin{array}{c}\text { Crystallization/nucleation } \\
\text { outcomes }\end{array}$ & $\begin{array}{l}\text { Ref } \\
\text { eren } \\
\text { ce }\end{array}$ \\
\hline \multirow{4}{*}{$\begin{array}{l}\text { PLA/PCL/ } \\
\text { PLLA- } \\
\text { PCL-PLLA }\end{array}$} & \multirow[t]{4}{*}{2001} & Neat PLA & \multirow{4}{*}{$\begin{array}{l}\text { PLOM isothermal } \\
\text { crystallization; } \\
\text { Isothermal and } \\
\text { non-isothermal } \\
\text { DSC }\end{array}$} & 115 & - & - & \multirow{4}{*}{$\begin{array}{l}\text { Addition of PCL promotes the } \\
\text { crystallization of PLA from the glassy } \\
\text { state regardless of PCL and PLLA- } \\
\text { PCL-PLLA content. The PLLA } \\
\text { spherulites growth rate kept constant } \\
\text { in all compositions. }\end{array}$} & \multirow[t]{4}{*}{59} \\
\hline & & $90 / 10$ & & 100 & - & - & & \\
\hline & & $80 / 20$ & & 100 & - & - & & \\
\hline & & $70 / 30$ & & 100 & - & - & & \\
\hline PDLA/PCL & 2006 & $\begin{array}{l}0-100 \quad \text { wt\% } \\
\text { of PCL }\end{array}$ & $\begin{array}{l}\text { DSC non- } \\
\text { isothermal } \\
\text { crystallization } \\
\text { PLOM isothermal } \\
\text { measurements }\end{array}$ & - & - & - & $\begin{array}{l}\text { The crystallization of PDLA was } \\
\text { enhanced by PCL resulting in an } \\
\text { increase of PDLA } X c \text { in the } 80 / 20 \\
\text { PDLA/PCL. }\end{array}$ & 63 \\
\hline
\end{tabular}




\begin{tabular}{|c|c|c|c|c|c|c|c|c|}
\hline \multirow{11}{*}{$\begin{array}{l}\text { PLA/PCL } \\
\text { /talc }\end{array}$} & \multirow[t]{11}{*}{2010} & Neat PLA & \multirow{11}{*}{$\begin{array}{l}\text { DSC non- } \\
\text { isothermal } \\
\text { crystallization }\end{array}$} & 109 & - & - & \multirow{11}{*}{$\begin{array}{l}\text { 40/60 PLA/PCL blend: Increase in } \\
\text { PCL } T_{c} \text { during cooling process and } \\
\text { slight decrease in PLA } T_{c c} \text { during } \\
\text { subsequent heating process. Addition } \\
\text { of talc results in remarkable increase } \\
\text { in both PCL and PLA crystallization } \\
\text { temperature. }\end{array}$} & \multirow[t]{11}{*}{44} \\
\hline & & Neat PCL & & - & - & 30 & & \\
\hline & & $40 / 60$ & & 106 & - & 39 & & \\
\hline & & $70 / 30 / 1$ & & - & 110 & 36 & & \\
\hline & & Neat PCL & & - & - & - & & \\
\hline & & $80 / 20$ & & 102.1 & - & - & & \\
\hline & & $50 / 50$ & & 105.9 & - & - & & \\
\hline & & $20 / 80$ & & 103.2 & - & - & & \\
\hline & & $80 / 20$ & & 121.2 & - & - & & \\
\hline & & $80 / 20 / 2.5$ & & 114.4 & - & - & & \\
\hline & & $80 / 20 / 7.5$ & & 98.1 & - & - & & \\
\hline \multirow{11}{*}{$\begin{array}{l}\text { PLA/PCL/ } \\
\text { EC-bp }\end{array}$} & \multirow[t]{11}{*}{2013} & Neat PLA & \multirow{11}{*}{$\begin{array}{l}\text { DSC non- } \\
\text { isothermal } \\
\text { crystallization. } \\
\text { WAXD }\end{array}$} & 126.8 & - & - & \multirow{11}{*}{$\begin{array}{l}\text { Addition of PCL accelerates the cold } \\
\text { crystallization of PLA and Xc } \\
\text { increases. } \\
\text { EC-bp plays the role of cross-linking } \\
\text { agent, thus decreasing the } \\
\text { crystallization rate of PLA. }\end{array}$} & \multirow[t]{11}{*}{60} \\
\hline & & Neat PCL & & - & - & - & & \\
\hline & & $90 / 10$ & & 121.6 & - & - & & \\
\hline & & $80 / 20$ & & 119.6 & - & - & & \\
\hline & & $70 / 30$ & & 115.5 & - & - & & \\
\hline & & $70 / 30 / 0.5$ & & 121 & - & - & & \\
\hline & & $70 / 30 / 1$ & & 124.2 & - & - & & \\
\hline & & $70 / 30 / 2$ & & 128.7 & - & - & & \\
\hline & & $90 / 10$ & & 90.52 & - & - & & \\
\hline & & $80 / 20$ & & 90.09 & - & - & & \\
\hline & & $70 / 30$ & & 90.39 & - & - & & \\
\hline $\begin{array}{l}\text { PLA/PCL/ } \\
\text { POSS }\end{array}$ & 2014 & $\begin{array}{l}70 / 30 \text { wt } \% \\
\text { with } 2 \% \text { of } \\
\text { different } \\
\text { kind } \\
\text { POSS }\end{array}$ & $\begin{array}{l}\text { DSC non- } \\
\text { isothermal nol } \\
\text { crystallization }\end{array}$ & - & - & - & $\begin{array}{l}\text { The addition of PCL and } \\
\text { Octaisobutyl-POSS results in slight } \\
\text { changes in PLA crystallization. The } \\
\text { presence of POSS limits PCL } \\
\text { crystallization. }\end{array}$ & 61 \\
\hline $\begin{array}{l}\mathrm{PLA} / \mathrm{PCL} / \\
\mathrm{TiO}_{2}\end{array}$ & 2015 & $\begin{array}{l}30-70 \text { wt } \% \\
\text { of PCL with } \\
1-5 \text { wt } \% \text { of } \\
\mathrm{TiO}_{2} \text {. }\end{array}$ & $\begin{array}{l}\text { DSC non- } \\
\text { isothermal nol } \\
\text { crystallization }\end{array}$ & - & - & - & $\begin{array}{l}\text { PCL crystallinity kept constant and do } \\
\text { not change in the blends (despite the } \\
\text { presence of PLA, } \mathrm{TiO}_{2} \text { or } \\
\text { PLA+TiO } 2 \text { ). }\end{array}$ & 62 \\
\hline \multirow{4}{*}{$\begin{array}{l}\text { PLA/PCL/ } \\
\text { P(LA-ran- } \\
\text { CL)LMw }\end{array}$} & \multirow[t]{4}{*}{2016} & Neat PLA & \multirow{5}{*}{$\begin{array}{l}\text { PLOM isothermal } \\
\text { crystallization of } \\
\text { PLA, } \\
\text { Isothermal and } \\
\text { non-isothermal } \\
\text { DSC analysis. }\end{array}$} & 128.1 & - & - & \multirow{4}{*}{$\begin{array}{l}\text { Fractionated crystallization of PCL } \\
\text { phase, acceleration of PLA cold- } \\
\text { crystallization. The presence of } \\
\text { copolymers causes an enhancement in } \\
\text { the crystallization rate of both } \\
\text { polymers }\end{array}$} & \multirow[t]{5}{*}{38} \\
\hline & & Neat PCL & & - & - & 25.9 & & \\
\hline & & $80 / 20$ & & $\begin{array}{c}100.5 / 1 \\
54\end{array}$ & - & $\begin{array}{c}15.8 / 3 \\
2.1 \\
\end{array}$ & & \\
\hline & & $78.4 / 19.6 / 2$ & & $\begin{array}{c}96.3 / 15 \\
1.5 \\
\end{array}$ & 110.8 & $\begin{array}{c}15.3 / 3 \\
1.6 \\
\end{array}$ & & \\
\hline $\begin{array}{l}\text { PLA/PCL/ } \\
\text { P(LA-ran- } \\
\text { CL)HMw }\end{array}$ & 2016 & $78.4 / 19.6 / 2$ & & $\begin{array}{c}93.4 / 15 \\
2.2\end{array}$ & 95.8 & 34.7 & & \\
\hline \multirow[t]{5}{*}{ PLA/PCL } & \multirow[t]{5}{*}{2016} & Neat PLA & \multirow{5}{*}{$\begin{array}{l}\text { DSC non- } \\
\text { isothermal } \\
\text { crystallization }\end{array}$} & 129 & - & - & \multirow{5}{*}{$\begin{array}{l}\text { Fractionated crystallization of PCL } \\
\text { phase has been observed in } 70 / 30 \\
\text { PLA/PCL. Pure PLA is amorphous } \\
\text { and the addition of PCL results in an } \\
\text { increase of the PLA cold } \\
\text { crystallization and } X c \text {. }\end{array}$} & \multirow[t]{5}{*}{64} \\
\hline & & Neat PCL & & - & - & - & & \\
\hline & & $70 / 30$ & & 125 & - & - & & \\
\hline & & $50 / 50$ & & 124 & - & - & & \\
\hline & & $30 / 70$ & & 122 & - & - & & \\
\hline PLA/PCL & 2016 & $\begin{array}{l}0-100 \text { wt } \% \\
\text { of PCL using } \\
\text { three } \\
\text { different } \\
\text { PLA grade }\end{array}$ & $\begin{array}{l}\text { DSC non- } \\
\text { isothermal } \\
\text { crystallization }\end{array}$ & - & - & - & $\begin{array}{l}\text { Addition of PCL resulted in (i) large } \\
\text { increase in the nucleation density and } \\
\text { (ii) faster PLA cold crystallization } \\
\text { kinetics. PCL crystallinity decreased } \\
\text { with the increase in PLA content. }\end{array}$ & 66 \\
\hline \multirow{4}{*}{$\begin{array}{l}\text { PLA/PCL/ } \\
\text { PLA-b-PC }\end{array}$} & \multirow[t]{4}{*}{2017} & Neat PLA & \multirow{5}{*}{$\begin{array}{l}\text { Isothermal and } \\
\text { non-isothermal } \\
\text { DSC, } \\
\text { PLOM isothermal } \\
\text { analysis of PLA } \\
\text { crystallization }\end{array}$} & 129.1 & - & - & \multirow{5}{*}{$\begin{array}{l}\text { Fractionated crystallization of PCL } \\
\text { phase }(20 \text { wt } \%) \text { during the cooling } \\
\text { scan, and accelerated cold } \\
\text { crystallization of PLA phase due to } \\
\text { the nucleation effect of PCL (molten) } \\
\text { droplets on glassy PLA. }\end{array}$} & \multirow[t]{5}{*}{16} \\
\hline & & Neat PCL & & 110.8 & - & 28.8 & & \\
\hline & & $80 / 20$ & & - & - & $\begin{array}{c}21.7 / 3 \\
1.8 \\
\end{array}$ & & \\
\hline & & $80 / 20 / 2$ & & - & 119.2 & $\begin{array}{c}4.6 / 23 \\
.1\end{array}$ & & \\
\hline $\begin{array}{l}\text { PLA/PCL/ } \\
\text { PC }\end{array}$ & 2017 & $80 / 20 / 2$ & & - & 93.1 & $\begin{array}{c}12 / 19 \\
7\end{array}$ & & \\
\hline
\end{tabular}




\begin{tabular}{|l|l|l|l|l|l|l|l|}
\hline PLA/PCL & 2018 & $\begin{array}{l}0-50 \mathrm{wt} \% \text { of } \\
\text { PCL }\end{array}$ & $\begin{array}{l}\text { DSC non- } \\
\text { isothermal } \\
\text { crystallization; } \\
\text { DSC and PLOM } \\
\text { isothermal } \\
\text { crystallization of } \\
\text { PCL }\end{array}$ & - & - & - & $\begin{array}{l}\text { Overall isothermal crystallization } \\
\text { kinetics revealed that the presence of } \\
\text { 20-40 wt\% of PLA enhances the } \\
\text { crystallization ability of PCL. Growth } \\
\text { rate of PCL found to be independent } \\
\text { of PLA content. }\end{array}$ \\
\hline
\end{tabular}

The crystallization of PLA as a major component in PLA/PCL blends will be considered first. A clear acceleration of PLA overall crystallization rate in the presence of 20 wt\% PCL has been reported [16]. For example, the time to complete crystallization at $120{ }^{\circ} \mathrm{C}$ is $1.5 \mathrm{~min}$ in the blend, with respect to 8 minutes in the pure PLA. A faster overall crystallization is consistently found for neat and compatibilized blends in a wider temperature range, as shown in Figure 8 [38]. Considering the results of neat PLA and 80/20 uncompatibilized PLA/PCL blend, we can notice, beside the increase of the overall crystallization rate, a shift of the maximum rate towards lower crystallization temperature and a substantial narrowing of the bell-shaped curve.

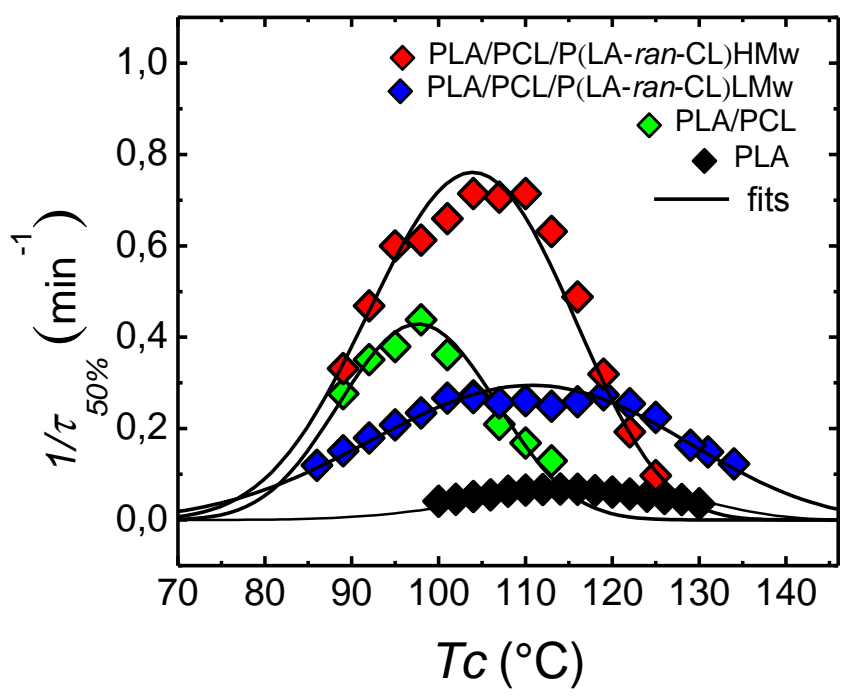

Figure 8. Overall crystallization rate $\left(1 / \tau_{50 \%}\right)$ as a function of isothermal crystallization temperature $T c$ in neat PLA and blends with PCL 80/20. Results for blends compatibilized with Poly(lactide-ran-caprolactone) (P(LA-ran-CL)) of different molecular weights are also included. The solid lines represent a guide to the eye [38].

In order to account for the change in the temperature dependence of the overall crystallization rate (shape of the curve in Figure 8), the effect of PCL on the different stages of the crystallization process, i.e., primary nucleation and growth, should be considered.

Given the immiscibility of the polymers, a change in the growth rate of PLA by blending is not expected. In Figure 9, we can see optical micrographs of 80/20 PLLA/PCL blend at $125^{\circ} \mathrm{C}$ (Figure 9a), and in the molten state (Figure 9b) [59]. 


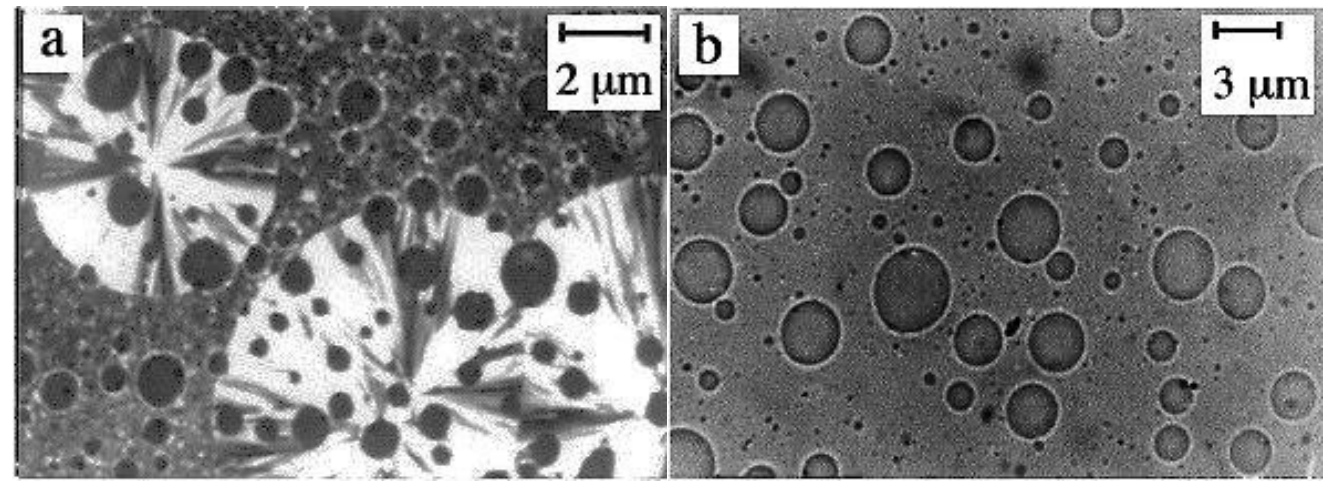

Figure 9: Optical micrographs of $80 / 20$ PLLA/PCL blend (a) at $125^{\circ} \mathrm{C}$ and (b) in the melt state. Adapted from [59].

The phase separation is evident, and the PCL droplets, which are molten at $125^{\circ} \mathrm{C}$, are not interfering with the growth of PLA spherulites, which simply proceed with their engulfment. The invariance of PLA growth rate between neat polymer and uncompatibilized PLA/PCL blend was quantitatively confirmed, as shown in Figure 10 [38]. No meaningful changes in the PLA spherulites growth rate $(\mathrm{G})$ can be detected in the blend, in the whole crystallization temperature range, unless compatibilizing copolymers were added to the systems.

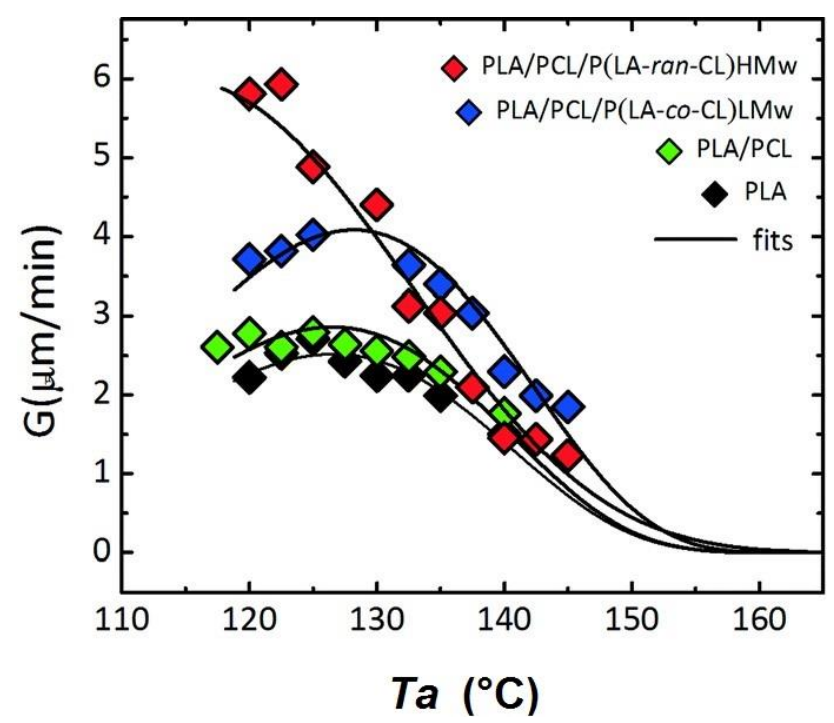

Figure 10. Spherulitic growth rate $G$ as a function of isothermal crystallization temperature (Tc) for neat PLA and 80/20 PLA/PCL blends, with or without P(LA-ran-CL) copolymers as compatibilizing agents. The solid lines are a guide to the eye [38].

Therefore, it seems apparent that the increase in PLA overall crystallization rate with the presence of PCL (Figure 8) can be explained only as a nucleation effect, either by the 
interface between the molten polymers of by some heterogeneity transferred to the PLA phase from the PCL bulk during the mixing process.

Similarly to the case of PLA/PBS blends, a distinct effect of PCL on the crystallization of PLA from the glassy state in their immiscible blend has also been extensively reported. [38,44,59,60,62,66,69-71]. A literature-based collection of PLA cold-crystallization temperatures as a function of PCL content is presented in Figure 11, according to the same normalization method employed in Figure 6. Despite differences among the systems are large, depending on the specific polymer grade, a clear reduction of $\Delta T c c$ values is observed when PCL is added to PLA. While the trend as a function of composition is not so clear, the nucleating effect of the PCL component on PLA, for most values reported in the literature, is pronounced for most systems.

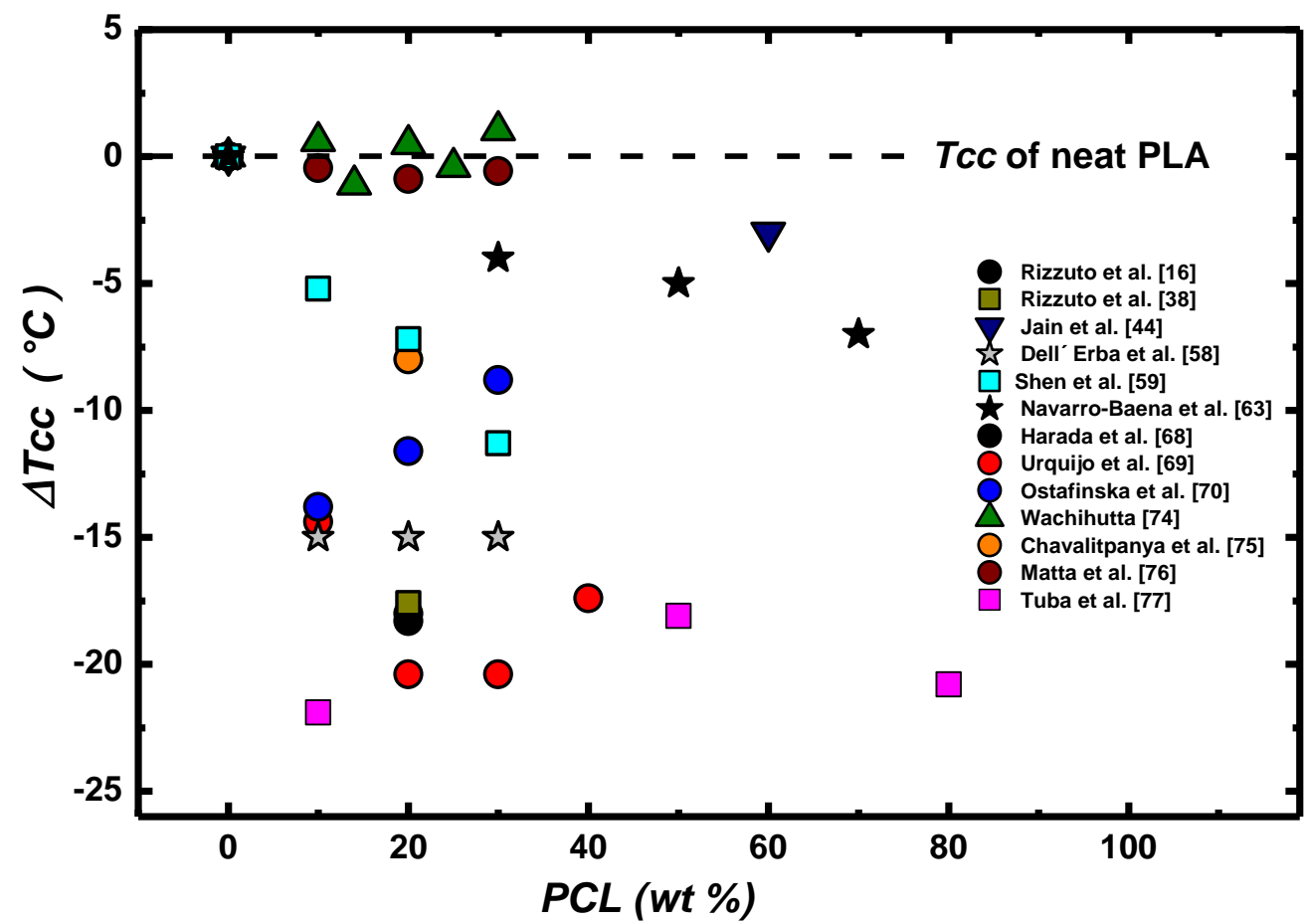

Figure 11: Cold crystallization temperature of PLA, as a function of PCL content in different PLA/PCL blends reported in literature.

It should be noted, however, that a fundamental difference exists between PCL and PBS, at the typical temperatures of PLA cold-crystallization. Indeed, while in PLA/PBS immiscible blend the de-vitrified PLA is in contact with semicrystalline PBS droplets, in the case of PLA/PCL blend, the nucleating effect might originate from a molten PCL phase. Alternatively, it could be hypothesized that nucleation of PLA occurs during the cooling stage, upon PCL crystallization, even though the PLA matrix is already in the glassy state (at 
$\left.T_{c, P C L}\right)$. Note that this possibility is not contemplated for PLA/PBS blend, since poly(butylene succinate crystallizes above the glass transition of polylactide. In order to better understand the peculiar nucleation mechanism upon cold-crystallization of PLA in its immiscible blend with PCL, a purposely designed thermal history has been applied by Müller et al. [16].

According to this protocol, the samples were quenched below $T_{g, P L A}$, and annealed at progressively lower temperatures for a fixed time, before re-heating to measure PLA coldcrystallization temperature and PCL crystallinity (by its melting enthalpy). The relevant results are reported in Figure 12 [16].

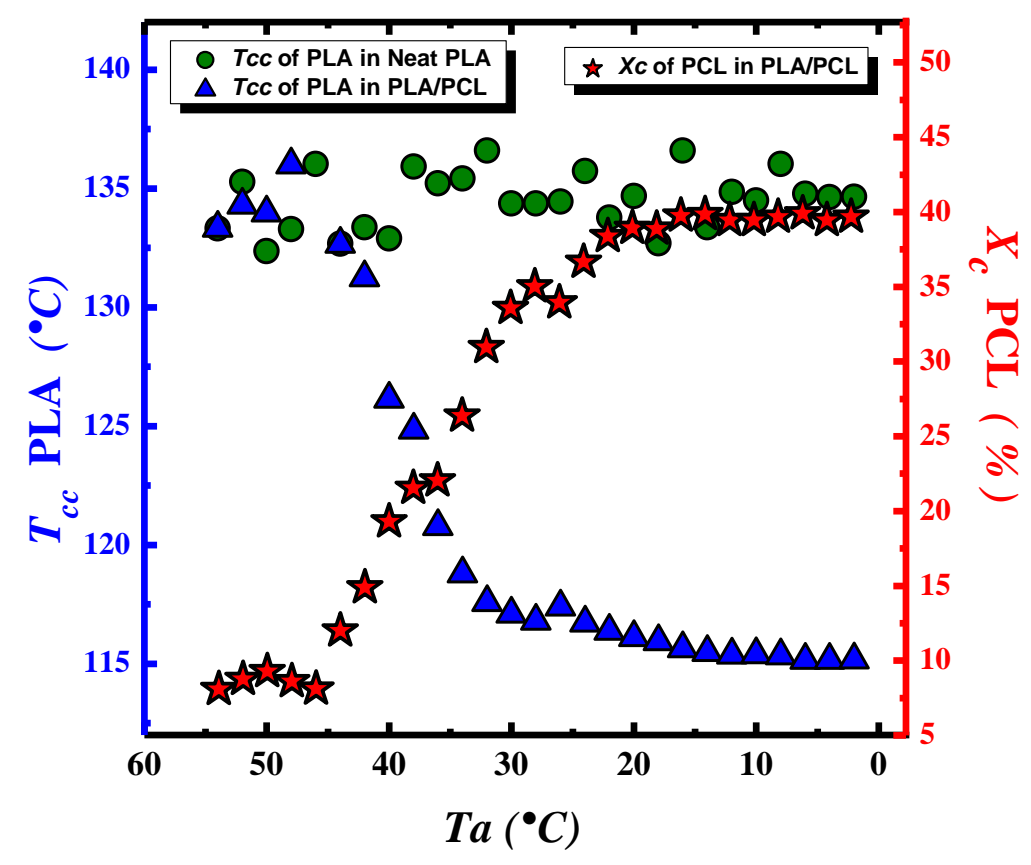

Figure 12. Cold-crystallization temperature of PLA $\left(T_{c c}\right)$ and crystallinity degree of PCL $(X c)$ as a function the annealing temperature $T a$. Data related to neat PLA and PLA/PCL 80/20 blend are shown [16].

Crystallization of PCL occurs in a rather broad temperature range, from about 45 to 20 ${ }^{\circ} \mathrm{C}$. Concomitantly with the increase of PCL crystallinity obtained by lowering the annealing temperature, the cold-crystallization temperature of PLA decreases smoothly from 135 to 115 ${ }^{\circ} \mathrm{C}$, indicating a nucleation effect of the developing PCL crystals on the glassy PLA matrix. It should be noted that a similar acceleration of PLA cold-crystallization is not observed in pure PLA, when annealed for the same time in the same temperature range (see Figure 12). If the blend is compatibilized, resulting in smaller PCL droplets and higher PLA/PCL interfacial area, a higher nucleating efficiency of PCL crystals on PLA cold-crystallization can be found 
[16]. Although is now well established that PLA can nucleate at temperatures below its glass transition $[79,80]$, despite the extremely low mobility, the presence of PCL crystals seems to accelerate this process. The exact mechanism of nucleation in this peculiar situation has not been established, but a role of the stresses developing at the interface between the two polymers, upon PCL crystallization, can be speculated.

The effect of the addition of a third polymeric component to PLA/PCL immiscible blend on the crystallization of PLA was reported in a number of works $[16,38,59,75,76]$. In general, an acceleration of PLA crystallization kinetics can be observed, although the exact origin of this effect depends on the balance between the miscibility of the additive with the PLA matrix and its compatibilizing action.
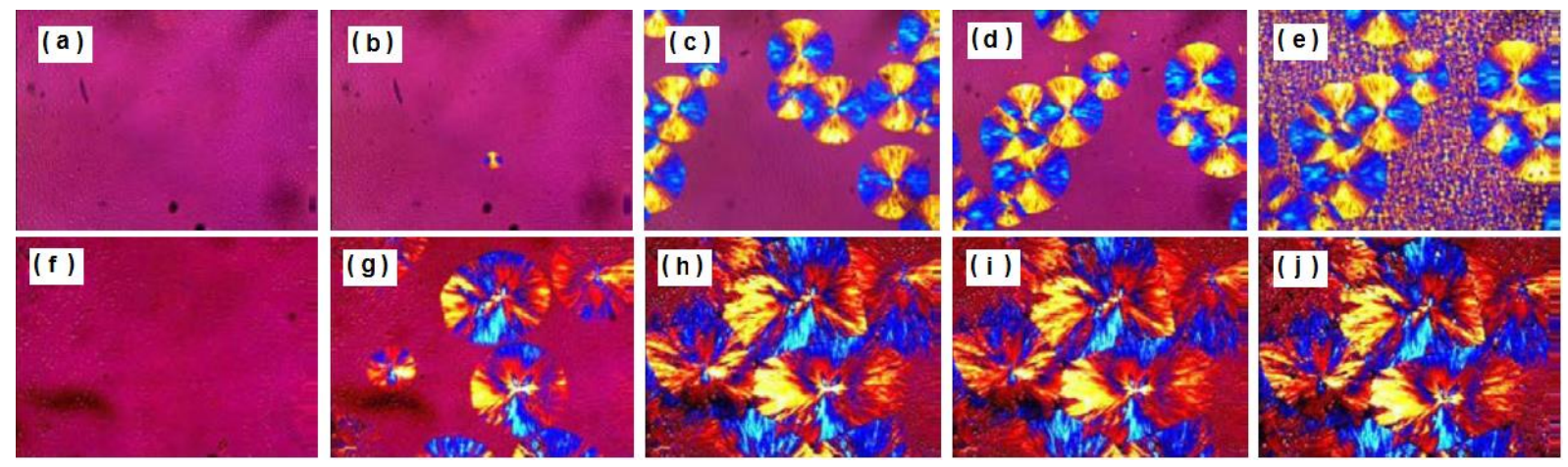

Figure 13: PLOM images during crystallization of 85/15 PLLA/PCL blends either neat (a-e) or with $5 \mathrm{wt} \%$ Pluronic copolymer (f-j). Pictures are taken during stepwise crystallization at (a, f) $141^{\circ} \mathrm{C}, 0 \mathrm{~min}$; (b,g) and (g) $141^{\circ} \mathrm{C}, 30 \mathrm{~min}$; (c) and (h) $141^{\circ} \mathrm{C}, 90 \mathrm{~min}$; (d,i) $127^{\circ} \mathrm{C}$ and $(\mathrm{e}, \mathrm{j})$ $37^{\circ} \mathrm{C}[75]$.

Rizzuto et al. [16] have investigated the crystallization behavior of PLA/PCL 80/20 wt $\%$ with the addition of $2 \mathrm{wt} \%$ of poly(L-lactide-block-carbonate) copolymers with different compositions. A large effect on the morphology, with the formation of sub-micron PCL droplets in the best case, was detected, together with a minor decrease in PLA glass transition temperature. Given that PLA spherulitic growth rate was not affected, the measured enhancement of overall crystallization kinetics with respect to the neat blend in the presence of the block copolymer was attributed to a nucleating effect of the PCL interfaces. On the other hand, when the added third polymer is partially miscible, plasticization effects can arise, causing higher PLA chain mobility and faster crystal growth rates. This is the case for instance of the already mentioned P(LA-ran-CL) copolymers [38] (see Figure 10) or Pluronic (PEG-PPG-PEG triblock copolymers) [75]. In this latter system, despite the block chain architecture, a partial miscibility exists, and it results in a faster PLA cold and melt- 
crystallization. Figure 13 indeed shows that, upon cooling a 85/15 PLA/PCL blend, larger spherulites develop when few percent of Pluronic block copolymer is added.

A relatively small number of works reported on the crystallization of the PCL components of immiscible PLLA/PCL blends. Opposite effects are observed, depending on the specific morphology. Few studies $[38,44,65]$ have reported an enhancement of PCL crystallization during cooling upon the addition of PLA. This is a consequence of the nucleation at the interface with the previously crystallized PLA phase, as shown in the PLOM micrographs of Figure 14. A 32/68 PLLA/PCL immiscible blend is first crystallized at $120^{\circ} \mathrm{C}$ and subsequently cooled to $35^{\circ} \mathrm{C}$. At $120^{\circ} \mathrm{C}$ (Figure 14a), only PLA is able to crystallize, whereas the PCL is molten and dispersed in between the PLA spherulites (see as an example the white oval marker in Figure 14a, where molten PCL is shown). By quenching to $35^{\circ} \mathrm{C}$ (Figure 14b), the PCL crystallization start clearly at the interface with crystalline PLA, developing a transcrystalline morphology clearly visible within the white oval region depicted [46].

(a) $120{ }^{\circ} \mathrm{C}$

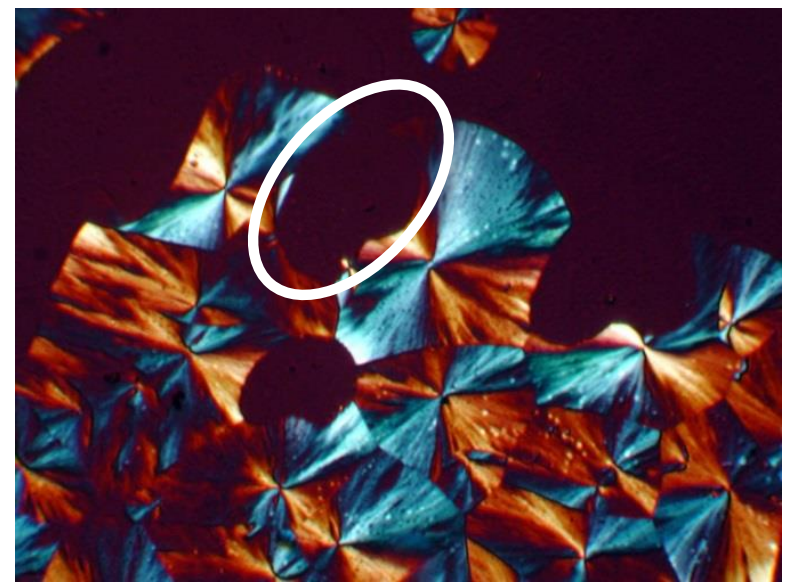

(b) $35{ }^{\circ} \mathrm{C}$

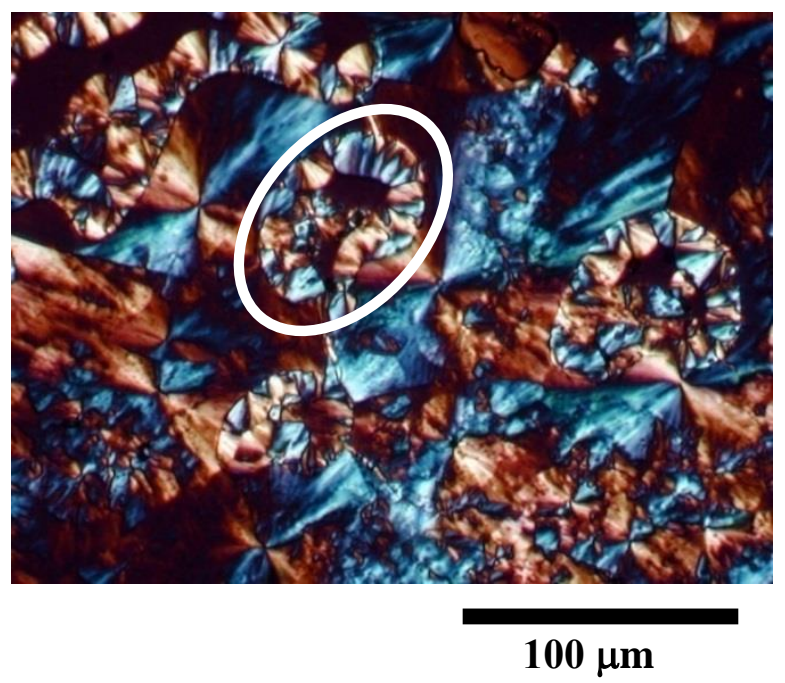

Figure 14: Optical micrographs of 32/68 PLLA/PCL immiscible blends during crystallization (a) at $120^{\circ} \mathrm{C}$, and (b) at $35^{\circ} \mathrm{C}$. Figure adapted from ref. [46].

On the other hand, when PCL is the minority phase dispersed in small domains within the PLA matrix, fractionated crystallization and a decrease in PCL crystallinity was found $[16,38,61,64,78]$. As an example, the DSC cooling traces of PLA, PCL and 80/20 PLLA/PCL blends containing different kind of compatibilizing agents poly(L-lactide-block-carbonate) (PLA-b-PC) are shown in Figure 15. In neat PLA/PCL blends, two different populations of 
droplets are present. The majority of them crystallize at the same temperature as bulk PCL $\left(32^{\circ} \mathrm{C}\right)$, indicating that they still contain most of the heterogeneities present in the original PCL sample. A minority of PCL droplets contains less efficient nucleating impurities, and solidifies about $10{ }^{\circ} \mathrm{C}$ lower. Upon addition of PLA-b-PC compatibilizer, droplet size is decreased and the larger fraction of droplets crystallizes at even lower temperatures, possibly nucleated at the interface with glassy PLA [16].

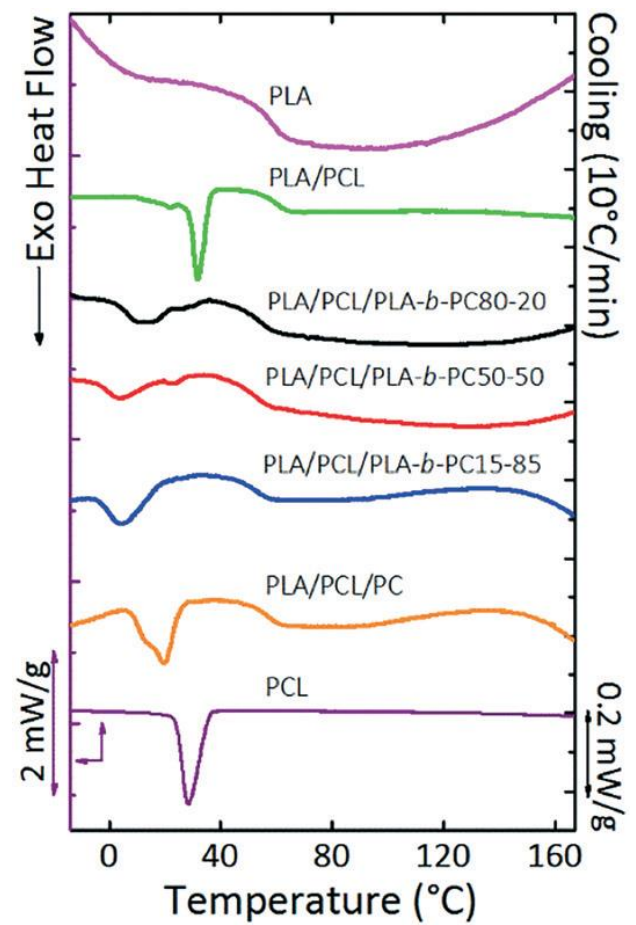

Figure 15. DSC cooling curves at $10{ }^{\circ} \mathrm{C} / \mathrm{min}$, of neat PLA, neat PCL, PLA/PCL blends, and PLA/PCL/compatibilizer blends. Adapted from [16].

\subsection{Poly (butylene succinate) / Poly (e-caprolactone) immiscible blends}

Blends of poly(butylene succinate) and poly( $\varepsilon$-caprolactone) are interesting because of the good mechanical properties shown by the two parent homopolymers, both of which are constituted by flexible chains. This notwithstanding, only very few works focused on the study of PBS/PCL blends, either neat or compatibilized. [81-83]

Qiu et al. [82] explored the effect of composition on crystallization and melting behavior of PBS/PCL blends. Figure 16 shows the DSC cooling curves of all samples at a cooling rate of $5^{\circ} \mathrm{C} / \mathrm{min}$. 


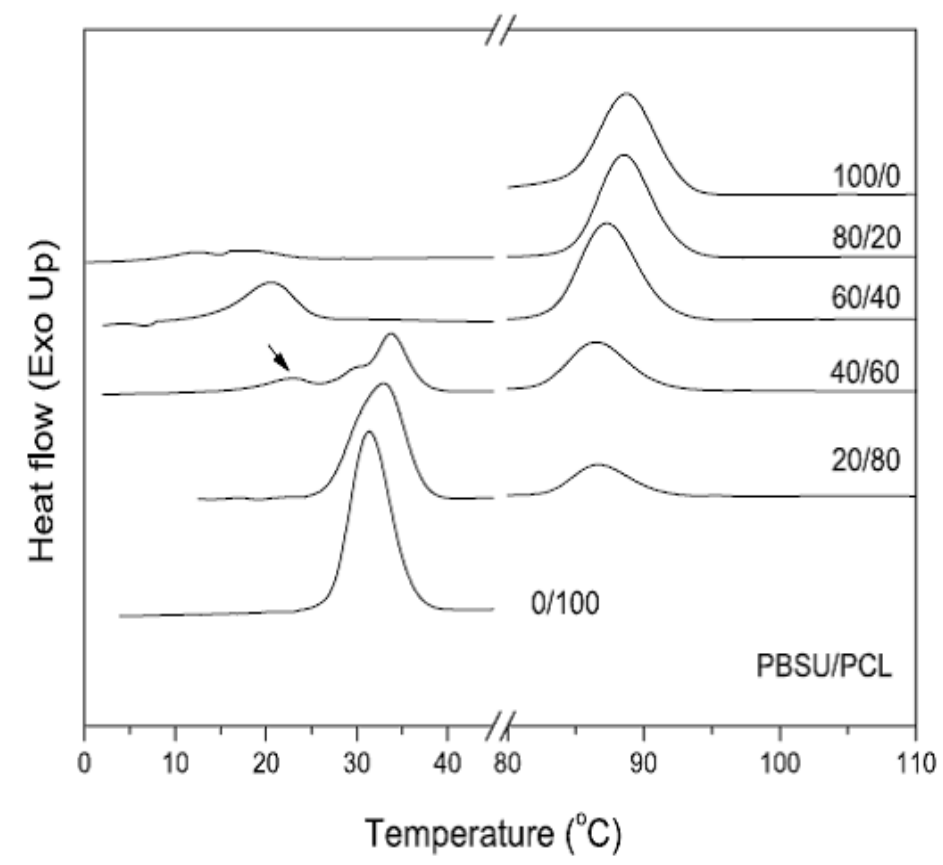

Figure 16: Non-isothermal crystallization from the melt of PBS/PCL blends with different compositions at a cooling rate of $5{ }^{\circ} \mathrm{C} / \mathrm{min}$ [82].

On the PBS-rich part of the composition range, no significant effect of PCL addition on the crystallization of the major component was noticed. On the other hand, a minor content ( $<40 \mathrm{wt} \%)$ of PBS causes at first the increase in PCL crystallization rate, i.e., an upward shift of the crystallization peak temperature. The same effect was reported for an 80/20 PBS/PCL blend, with an increase of $T_{c, P C L}$ of about $10{ }^{\circ} \mathrm{C}$ and the invariance of $T_{c, P B S}$ [82]. The enhanced PCL crystallization was attributed to a nucleation effect of the interfaces with previously crystallized PBS. When PCL becomes the minority phase, a large depression of the crystallization temperature is observed and multiple crystallization events, i.e., fractionated crystallization, is also evident. Fractionated crystallization is particularly clear in the 60/40 PBS/PCL blend, [82] which is an unusual composition for the phenomenon. However, a detailed morphological analysis that could explain the observation has not been carried on.

Fractionated crystallization and finer dispersion of PCL phase at lower contents is also associated with a substantial decrease of its crystallinity, indicating a hindrance of the crystallized matrix on PCL structuring.

\subsection{Blends of poly (hydroxybutyrate) and other bio-based polyesters}

Poly(3-hydroxybutyrate) (PHB) is a biodegradable thermoplastic polyester which can be obtained via a biotechnological process by means of selected bacteria. PHB is a highly 
crystalline polymer with high stiffness, and a melting and glass transition temperatures of around 170 and $5{ }^{\circ} \mathrm{C}$, respectively.

Blends of PHB with PLA have been investigated, with the aims of reducing PHB crystallinity (detrimental for some applications) on one side; and improve the properties of PLA (e.g., gas barrier properties for food packaging application) on the other side. The degree of compatibility between the PLA and PHB in their blends affects the crystallization behavior of the two components [43,62,84-97]. This section presents a summary of previous research on PLA/PHB blends in which the authors discussed, at least in part, the crystallization behavior. The results are summarized in Table 4.

Table 4. Main experimental works on PHB/PLA blends, with emphasis on nucleation and crystallization.

\begin{tabular}{|c|c|c|c|c|c|c|c|c|}
\hline Sample & $\begin{array}{c}\text { Publication } \\
\text { year }\end{array}$ & $\begin{array}{l}\text { Composition } \\
\text { wt } \%\end{array}$ & $\begin{array}{l}\text { Crystallization } \\
\text { /nucleation } \\
\text { conditions and } \\
\text { technics }\end{array}$ & $\begin{array}{l}T c c \\
\text { of } \\
\text { PLA } \\
\left({ }^{\circ} \mathrm{C}\right)\end{array}$ & $\begin{array}{l}T c \text { of } \\
\text { PLA } \\
\left({ }^{\circ} \mathrm{C}\right)\end{array}$ & $\begin{array}{l}\text { Tc of } \\
\mathrm{PHB} \\
\left({ }^{\circ} \mathrm{C}\right)\end{array}$ & $\begin{array}{c}\text { Crystallization/nucleation } \\
\text { outcomes }\end{array}$ & $\begin{array}{l}\text { Ref } \\
\text { eren } \\
\text { ce }\end{array}$ \\
\hline PLA/PHB & 2006 & $50 / 50$ & $\begin{array}{l}\text { FTIR } \\
\text { spectroscopy; } \\
\text { stepwise } \\
\text { isothermal } \\
\text { crystallization of } \\
\text { the two polymers }\end{array}$ & - & - & - & $\begin{array}{l}\text { Crystallization mechanism of PLA } \\
\text { not affected by PHB presence, but } \\
\text { kinetics is retarded. Possible dilution } \\
\text { effect. PHB crystallization rate after } \\
\text { solidification of PLLA is depressed } \\
\text { due to segregation/confinement of the } \\
\text { polymer in the interfibrillar or } \\
\text { interlamellar region of PLA } \\
\text { spherulites. }\end{array}$ & 84 \\
\hline PLA/PHB & 2011 & $\begin{array}{l}0-100 \mathrm{wt} \% \\
\text { of PHB }\end{array}$ & $\begin{array}{l}\text { PLOM; } \\
\text { DSC non- } \\
\text { isothermal } \\
\text { crystallization; } \\
\text { WAXD; } \\
\text { FTIR }\end{array}$ & - & - & - & $\begin{array}{l}\text { PHB acts as a nucleating agent for } \\
\text { PLA, leading to an enhancement in } \\
\text { PLA cold-crystallization rate and } \\
\text { crystallinity. } \\
\text { The crystallization rate of PHB during } \\
\text { cooling is also accelerated. }\end{array}$ & 91 \\
\hline \multirow{3}{*}{$\begin{array}{l}\text { PLA/PHB/ } \\
\text { Lapol }\end{array}$} & \multirow[t]{3}{*}{2012} & Neat PLA & \multirow{3}{*}{$\begin{array}{l}\text { DSC non- } \\
\text { isothermal } \\
\text { crystallization; } \\
\text { XRD }\end{array}$} & 115 & - & - & \multirow{3}{*}{$\begin{array}{l}\text { No meaningful effect of PHB on the } \\
\text { crystallization behavior of PLA. The } \\
\text { addition of Lapol (plasticizer) } \\
\text { increases PLA crystallinity. }\end{array}$} & \multirow[t]{3}{*}{96} \\
\hline & & $75 / 25$ & & 115 & - & - & & \\
\hline & & $75 / 25 / 7$ & & 120 & - & - & & \\
\hline \multirow{5}{*}{$\begin{array}{l}\text { PLA/PHB/t } \\
\text { alc }\end{array}$} & \multirow[t]{5}{*}{2013} & $90 / 10$ & \multirow{5}{*}{$\begin{array}{l}\text { DSC non- } \\
\text { isothermal and } \\
\text { isothermal } \\
\text { crystallization; } \\
\text { FT-IR; PLOM. }\end{array}$} & 86.3 & - & - & \multirow{5}{*}{$\begin{array}{l}\text { PHB acted as a nucleating agent for } \\
\text { PLA. Further increases in PLA } \\
\text { crystallization kinetics was found by } \\
\text { addition of talc. } \\
\text { PLOM revealed that addition of } 10 \\
\text { wt } \% \text { PHB resulted in large increase in } \\
\text { PLA nucleation density. A further } \\
\text { increase in PLA nucleation density } \\
\text { was found with the addition of talc. } \\
\text { PHB crystallization was inhibited by } \\
\text { the presence of PLA and talc. }\end{array}$} & \multirow[t]{5}{*}{43} \\
\hline & & $90 / 10 / 0.5$ & & 86.2 & - & - & & \\
\hline & & $90 / 10 / 1$ & & 76.5 & - & - & & \\
\hline & & $90 / 10 / 2$ & & 83.3 & - & - & & \\
\hline & & $90 / 10 / 5$ & & 76.6 & - & - & & \\
\hline \multirow{3}{*}{$\begin{array}{l}\text { PLA/PHB/ } \\
\text { CNC }\end{array}$} & \multirow[t]{3}{*}{2014} & Neat PLA & \multirow{4}{*}{$\begin{array}{l}\text { XRD } \\
\text { F-TIR, } \\
\text { DSC non- } \\
\text { isothermal } \\
\text { crystallization }\end{array}$} & 82.5 & - & - & \multirow{4}{*}{$\begin{array}{l}\text { Addition of PHB, CNC or CNCs } \\
\text { resulted in a faster PLA cold } \\
\text { crystallization rate. While addition of } \\
\text { binary PHB/CNC or PHB/CNCs } \\
\text { resulted in increase of } T_{c c} \text { of PLA due } \\
\text { to lower chain mobility. }\end{array}$} & \multirow[t]{4}{*}{93} \\
\hline & & $75 / 25$ & & 66.4 & - & - & & \\
\hline & & $71.25 / 23.75 / 5$ & & 70.9 & - & - & & \\
\hline $\begin{array}{l}\text { PLA/PHB/ } \\
\text { CNCs }\end{array}$ & 2014 & $71.25 / 23.75 / 5$ & & 72.1 & - & - & & \\
\hline \multirow{5}{*}{$\begin{array}{l}\text { PLA/PHB/ } \\
\text { ATBC/CA } \\
\text { T }\end{array}$} & \multirow[t]{5}{*}{2014} & Neat PLA & \multirow{5}{*}{$\begin{array}{l}\text { DSC non- } \\
\text { isothermal } \\
\text { crystallization; } \\
\text { XRD analysis. }\end{array}$} & 118.1 & - & - & \multirow{5}{*}{$\begin{array}{l}\text { Addition of PHB result in lowering } \\
\text { the crystallization rate of PLA thus } \\
\text { the PLA } T_{c c} \text { shifted to higher } \\
\text { temperatures. PLA } T_{c c} \text { decreases upon } \\
\text { addition of } 15 \mathrm{wt} \% \text { of ATBC due to } \\
\text { its plasticizing effect. } \\
\text { Presence of catechin increased PLA }\end{array}$} & \multirow[t]{5}{*}{94} \\
\hline & & $75 / 25 / 0 / 0$ & & 130 & - & - & & \\
\hline & & $63.6 / 21.2 / 15 / 0$ & & 106.3 & - & - & & \\
\hline & & $71.1 / 23.7 / 0 / 5$ & & 150 & - & - & & \\
\hline & & $60 / 20 / 15 / 5$ & & 126 & - & - & & \\
\hline
\end{tabular}




\begin{tabular}{|c|c|c|c|c|c|c|c|c|}
\hline & & & & & & & $\begin{array}{l}T_{c c} \text {, due to specific intermolecular } \\
\text { interactions. }\end{array}$ & \\
\hline \multirow{3}{*}{$\begin{array}{l}\text { PLA/PHB/ } \\
\text { LIM }\end{array}$} & \multirow[t]{3}{*}{2014} & Neat PLA & \multirow{3}{*}{$\begin{array}{l}\text { DSC non- } \\
\text { isothermal } \\
\text { crystallization; } \\
\text { PLOM; } \\
\text { FT-IR }\end{array}$} & 123.3 & - & - & \multirow{3}{*}{$\begin{array}{l}\text { After blending, PHB play the role of } \\
\text { nucleating agent for PLA. Further } \\
\text { increase in PLA crystallinity was } \\
\text { found in PLA/PHB/LIM blend due to } \\
\text { the plasticizing effect of LIM. }\end{array}$} & \multirow[t]{3}{*}{95} \\
\hline & & $75 / 25$ & & 96.9 & - & - & & \\
\hline & & $63.75 / 21.25 / 15$ & & 77.4 & - & - & & \\
\hline $\begin{array}{l}\text { PLA/PHB } \\
\text { V/ TiO2 }\end{array}$ & 2015 & $\begin{array}{c}30-70 \mathrm{wt} \% \\
\text { of PHBV } \\
\text { with } 1-5 \\
\text { wt\% of } \\
\mathrm{TiO}_{2} .\end{array}$ & $\begin{array}{l}\text { DSC non- } \\
\text { isothermal } \\
\text { crystallization }\end{array}$ & - & - & - & $\begin{array}{l}\text { Addition of PHBV resulted in a faster } \\
\text { cold crystallization of PLA due to a } \\
\text { plasticizing effect, which provides } \\
\text { more mobility to PLA. }\end{array}$ & 62 \\
\hline \multirow{5}{*}{$\begin{array}{l}\text { PLA/PHB/ } \\
\text { ATBC/ } \\
\text { CNC }\end{array}$} & \multirow[t]{5}{*}{2015} & Neat PLA & \multirow{5}{*}{$\begin{array}{l}\text { XRD; FT-IR; } \\
\text { DSC non- } \\
\text { isothermal } \\
\text { crystallization }\end{array}$} & 82.5 & - & 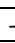 & \multirow{5}{*}{$\begin{array}{l}\text { PHB works as a nucleating agent for } \\
\text { the PLA phase. } \\
\text { CNCs and ATBC have a synergic } \\
\text { effect on PLA crystallization. }\end{array}$} & \multirow[t]{5}{*}{92} \\
\hline & & $75 / 25$ & & 66.4 & - & 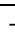 & & \\
\hline & & $63.75 / 21.25 / 15$ & & 75.5 & - & - & & \\
\hline & & $60 / 20 / 15 / 5$ & & 67.2 & - & - & & \\
\hline & & $60 / 20 / 15 / 5$ & & 95.8 & - & - & & \\
\hline
\end{tabular}

It should be noted that PLA/PHB can be miscible in the melt state if PLA of low molecular weight is employed [87,97]. Crystallization from a miscible melt can give rise to concomitant formation of PHB and PLA crystals at the same isothermal crystallization temperature and with similar kinetics [87]. Each phase crystallizes in a distinct type of spherulite, which interpenetrate when their growth front meet, due to the continued growth of one kind of lamellae in the interlamellar region of the other spherulite [97].

In the case of immiscible high-molecular weight polymer, the effect of PHB addition on PLA crystallization is not so well studied. Isothermal melt-crystallization of the PLA phase in a PLA/PHB 90/10 wt\% shows a large acceleration effect, with half crystallization times decreasing more than twice with respect to neat PLA. By means of PLOM measurement, the enhanced crystallization rate was correlated with an increase in PLA nucleation density [43]. On the other hand, Zhang et al. studied the isothermal crystallization of PLLA in the immiscible 50/50 PLLA/PHB blend, and observed a substantial depression of the crystallization rate [87]. This decrease in crystallization rate was attributed to a dilution effect, i.e., the PHB melt lowers the PLLA growth rate by reducing the amount of PLA chains in the growth front of the spherulite. Similarly, opposite effects of PHB on PLA cold-crystallization have been found. Several researchers reported an enhancement of the cold crystallization rate of PLA upon addition of small amounts of PHB [43,62,91-93]. In analogy, with what has been already discussed for PLA/PBS blends, the decrease of PLA $T_{c c}$ can be attributed to an interfacial nucleation effect on the crystalline PHB domains. On the contrary, Arrieta et al. [96] found that a $25 \mathrm{wt} \%$ of PHB in PLA/PHB blend caused a large increase in PLA coldcrystallization temperature from $118.1^{\circ} \mathrm{C}$ to $130^{\circ} \mathrm{C}$. This peculiar effect was ascribed to the possible occurrence of transesterification reactions between PHB and PLA during the blending step. 
Ternary systems containing immiscible PLA/PHB blend and various additives have also been investigated. Often, an acceleration in the crystallization rate of PLA is seen, typically due to (i) additional heterogeneous nucleation, for example from talc [43], cellulose nanocrystals (CNC) and surfactant modified cellulose nanocrystals (CNCs) [92,93]; and/or (ii) increase in the PLA chain mobility by a plasticizing effect of small soluble molecules such as acetyl (tributylcitrate) (ATBC) [92,94], and Limonene (LIM) [95]. Interestingly, a delayed cold-crystallization is observed for blends containing catechin, probably as a result of hydrogen bond formation with PLA chains [94].

Concerning the crystallization of the PHB phase in the presence of PLA as a major blend component, a strong depression of its kinetics - or even the complete suppression of crystallization in the adopted conditions - is always reported [43, 91]. These results have been generally interpreted as a confinement effect imposed by the crystalline PLA matrix, because upon PLA spherulitic crystallization at higher temperatures, the amorphous PHB chains are segregated to the interlamellar/interfibrilar regions of PLA superstructures $[98,99]$. Such intimate contact between the phases usually arises when some degree of partial miscibility exists between the chains in the melt state [100]

Few works have also investigated the phase behavior and crystallization of PHB blends with other biodegradable polymers, namely PBS and PCL [101-103]. Ma et al. [101] prepared $\mathrm{PHB} / \mathrm{PBS}$ blends in the entire composition range, with the aim of improving the crystallizability of PHB by the addition of the second component. The blends were immiscible with typical sea-island morphology for asymmetric compositions and cocontinuous $\mathrm{PHB} / \mathrm{PBS}$ phases at 50/50 wt $\%$. Non isothermal crystallization revealed a clear increase in $T_{c, P H B}$ of up to $30{ }^{\circ} \mathrm{C}$ with PBS content. The crystallization of PBS is instead depressed when the polymer is the minor component. Ma et al. interpreted this result as a consequence of confinement by the crystalline PHB matrix, but it could also be due to changes in nucleation induced by impurity transfer phenomena. The increase of PHB crystallization rate in the presence of PBS was also noticeable in isothermal conditions, with half crystallization times which decreased more than 5 times in the blends with respect to the neat polymer, independently from the composition. This acceleration of crystallization kinetics was attributed to a nucleation effect of the interfaces with molten PBS domains, as supported by PLOM measurements during isothermal crystallization above the PBS melting point (Figure 17). 

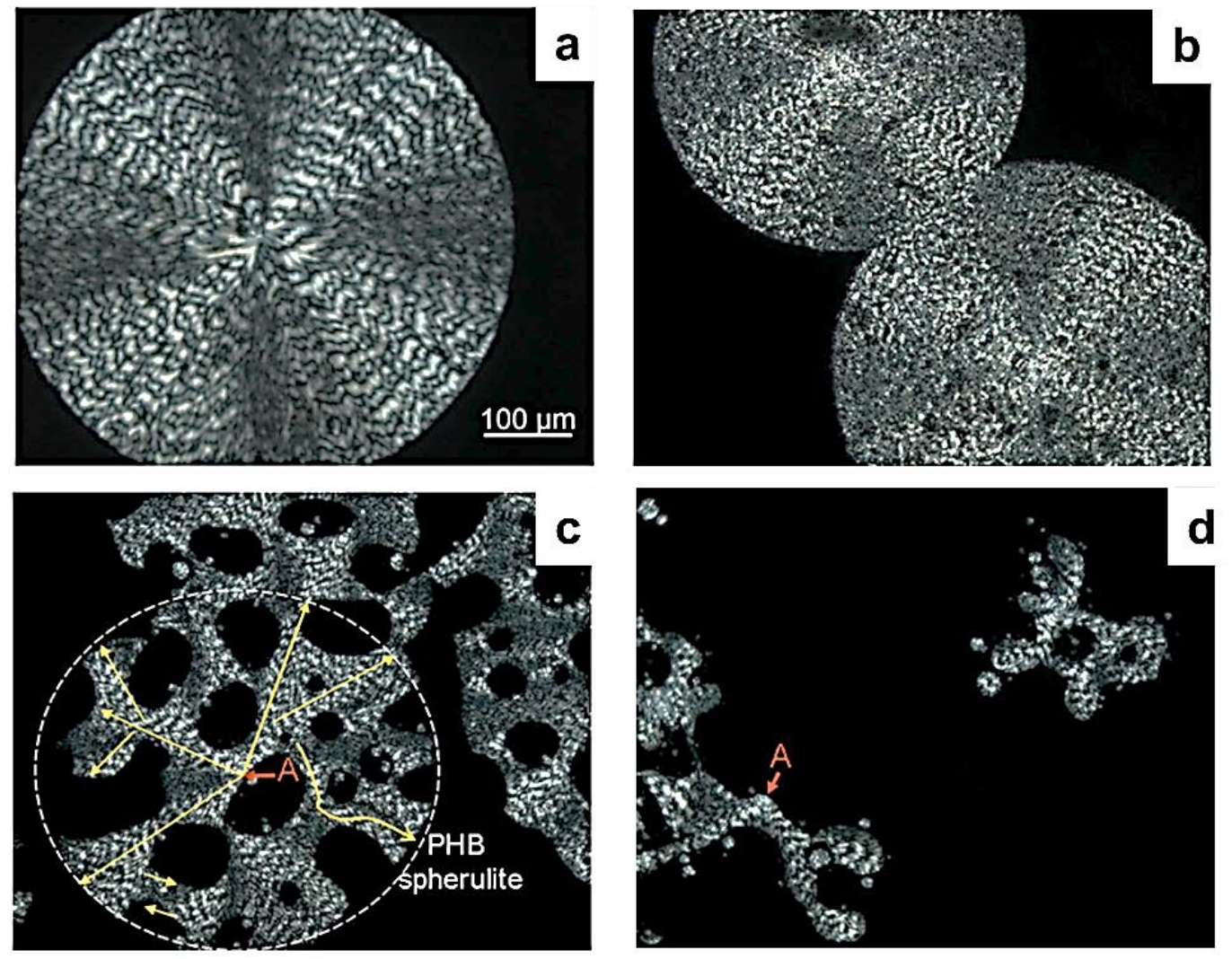

Figure 17: Polarized light optical microscopy during crystallization of PHB/PBS blends with various composition at $120{ }^{\circ} \mathrm{C}$. The PBS content in the blend is: a) $0 \%$; b) $30 \%$; c) $50 \%$ and d) $70 \%$ by weight. The development of PHB spherulite in c) is indicated by the arrow and the nucleation point by the letter "A". Adapted from ref. [101].

It can be seen that neat PHB (Figure 17a) crystallized in banded spherulites with very low nucleation density. Upon addition of $30 \mathrm{wt} \% \mathrm{PBS}$, the morphology is still spherulitic with dark molten domains of PBS engulfed in it. When the PHB content in the blend becomes 50\% or less, the crystals are forced to grow around the molten PBS domains, and the spherulitic structure becomes branched-like. However, the persistence of the banded motif allows one to identify the nucleation points (highlighted by the letter A in Figures $17 \mathrm{c}, \mathrm{d}$ ), at the interface with molten PBS domains. Moreover, nucleation of smaller molten PHB domains by contact with crystallizing PHB in larger droplets was also observed. It should be noted that a small reduction of PHB growth rate is measured, and attributed to the hindrance of molten PBS to the crystal development, although a limited miscibility between PHB and PBS has also been suggested [102]. 
Polyhydroxybutyrate/poly( $\varepsilon$-caprolactone) exhibit a molecular weight dependent miscibility. Lovera et al. [103] investigated the crystallization, morphology, and degradation behavior of PHB/PCL blends upon varying PCL molecular weight.

PHB/high molecular weight PCL blend was found to be immiscible. Analysis of the crystallization behavior after blending revealed fractionated crystallization of the PCL minor phase, with a depression of crystallization temperature of around $30{ }^{\circ} \mathrm{C}$. Blends with low molecular weight PCL were also biphasic, but the PHB-rich phase exhibited a partial miscibility with PCL, as inferred by the measured depression in the PHB melting and glass transition temperatures and by the increase in the spherulitic growth rate close to $T_{g}$. A decrease of PHB nucleation density in the partially miscible blend has also been reported, probably caused by impurity transfer between the two phases during blending.

\section{Conclusions and outlook}

In this review, we have concentrated on immiscible and mostly double crystalline thermoplastic polyester blends. The nucleation and crystallization of these complex materials greatly depends on their morphology, as determined by their composition, processing conditions and thermal history.

As far as the nucleation of double crystalline polyester blends is concerned, the component that crystallizes at higher temperatures can nucleate on: (a) existing heterogeneities which were either present in the parent homopolymer or transferred during melt blending from the second blend component or (b) on the interface between the two molten components. Notice than in the second case, or case (b) above, no epitaxial mechanism can be invoked to explain the heterogeneous nucleation that has been clearly documented by PLOM and DSC. Hence other causes must be found that could be related to secondary interactions between the immiscible phases, interfacial free energy differences or other unknown factors that clearly need more future research.

If the blend above with two crystallizable components is further cooled, after the first blend component has already crystallized, then the second polymer can be nucleated by: (a) existing heterogeneities which were either present in the parent homopolymer or transferred during blending from the second melt component or (b) on the interface between the previously crystallized blend component and the melt of the second component. In this second case, epitaxial nucleation is a possibility. In many cases, nucleation effects of the previously 
crystallized component on the second phase of the blend (that crystallizes at lower temperatures) have been reported. More peculiar effects like the nucleation of PCL droplets on glassy PLA matrices deserve more research in order to find how the nucleation can occur in the glassy state by interfacial contacts with crystalline polymeric droplets.

Another common occurrence is fractionated crystallization. This is a general process that has been found in many immiscible blends when a highly dispersed phase is produced and has been extensively studied and reviewed before, therefore it has not been the subject of extensive discussion in this review.

There are many more studies dealing with non-isothermal nucleation and nonisothermal crystallization of immiscible polyester blend components than isothermal studies. In the cases where the blends are immiscible, the spherulitic growth rates are clearly not affected, unless compatibilizers or plasticizers are employed. Hence, the overall isothermal crystallization kinetics of immiscible polyester blends is determined by the nucleation effects of one blend component on the other.

It is clear that future studies are needed in order to fully comprehend the solidification of these important bio-based and in many cases bio-degradable materials, as such understanding can clearly lead to tailoring their properties for applications where they can substitute traditional non-degradable plastic materials.

\section{Acknowledgements}

The authors would like to acknowledge funding by the BIODEST project ((RISE) H2020-MSCA-RISE-2017-778092).

\section{References}

1. Utracki LA, Wilkie C (Eds) (2014) Polymer Blends Handbook. Springer, New York.

2. Utracki LA (Ed) (2002) Polymer Blends Handbook, vol 2. Kluwer Academic Publishers, Dordrecht, Netherlands

3. Paul DR, Barlow JW (1979) A Brief Review of Polymer Blend Technology. In: Cooper SL, Estes GM (eds) multiphase polymers. Advances in Chemistry, Washington, p 315-335

4. Paul DR, Barlow JW (1980) Polymer Blends (or Alloys). J. Macromol. Sci., Rev. Macromol. Chem. Phys. 18:109-168 
5. Cor K, Martin VD, Christophe P, Robert J (1998) Strategies for compatibilization of polymer blends. Prog. Polym. Sci. 23:707-757

6. Supthanyakul R, Kaabbuathong N, Chirachanchai S (2016) Random poly(butylene succinate-co-lactic acid) as a multi-functional additive for miscibility, toughness, and clarity of PLA/PBS blends. Polymer 105:1-9

7. Dhibar AK, Kim JK, Khatua BB (2011) Cocontinuous Phase Morphology of Asymmetric Compositions of Polypropylene/High-density Polyethylene Blend by the Addition of Clay. J. Appl. Polym. Sci. 119:3080-3092

8. Tol RT, Mathot VBF, Reynaers H, Groeninckx G (2006) Relationship between Phase Morphology, Crystallization, and Semicrystalline Structure in Immiscible Polymer Blends. In: Harrats C, Thomas S, Droeninchx G (eds) Micro- and Nanostructured Multiphase Polymer Blend Systems Phase Morphology and Interfaces. Taylor \& Francis, USA, p 391-420

9. Cordova ME, Lorenzo AT, Müller AJ, Gani L, Tence-Girault S, Leibler L (2011) The Influence of Blend Morphology (Co-Continuous or Sub-Micrometer Droplets Dispersions) on the Nucleation and Crystallization Kinetics of Double Crystalline Polyethylene/Polyamide Blends Prepared by Reactive Extrusion. Macromol. Chem. Phys. 212:1335-1350

10. Pracella M (2013) Crystallization of polymer blends. In: Piorkowska E, Rutledge GC (eds) handbook of polymer crystallization. Wiley, New Jersey, p 287-325

11. Jabarin SA, Ardakani KM, Lofgren EA (2016) Crystallization and Melting Behavior in Polymer Blends. In: Isayev AI (ed) Encyclopedia of Polymer Blends volume 3: Structure. Wiley-VCH Verlag GmbH \& Co. KGaA, Weinheim, Germany, p 135-189

12. Michell RM, Müller AJ (2016) Confined crystallization of polymeric materials. Prog. Polym. Sci. 54-55, 183-213

13. Tien ND, Prud'homme RE (2017) Crystallization Behavior of Semicrystalline Immiscible Polymer Blends. In: Thomas S, Arif PM, Gowd B, Kalarikkal N (eds) Crystallization in Multiphase Polymer Systems. Elsevier, Amsterdam, p 181-212

14. Bartczak Z, Galeski A (1990) Homogeneous nucleation in polypropylene and its blends by small-angle light scattering. Polymer 31:2027-2038

15. Deng Y, Thomas NL (2015) Blending poly(butylene succinate) with poly(lactic acid): Ductility and phase inversion effects. Eur. Polym. J. 71:534-546

16. Rizzuto M, Marinetti L, Caretti D, Mugica A, Zubitur M, Müller AJ (2017) Can poly ( $\varepsilon$-caprolactone) crystals nucleate glassy polylactide?. CrystEngComm 19:3178 
17. Ma P, Cai X, Wang W, Duan F, Shi D, Lemstra PJ (2014) Crystallization Behavior of Partially Crosslinked Poly(b-hydroxyalkonates)/Poly(butylene succinate) Blends. J. Appl. Polym. Sci.131:41020

18. Frensch H, Harnischfeger P, Jungnickel BJ (1989) Fractionated Crystallization in Incompatible Polymer Blends. In: Utracky LA, Weiss RA (eds) Multiphase polymers: Blends and ionomers. American Chemical Society, Washington, pp 101-125

19. Müller AJ, Michell RM (2016) Differential Scanning Calorimetry of Polymers. In: Guo Q (ed) Polymer Morphology: Principles, Characterization, and Processing. John Wiley \& Sons, Inc., New Jersey, p 72-99

20. Morales RA, Arnal ML, Müller AJ (1995) The evaluation of the state of dispersion in immiscible blends where the minor phase exhibits fractionated crystallization. Polym. Bull. 35:379-386

21. Arnal ML, Matos ME, Morales RA, Santana OO, Müller AJ (1998) Evaluation of the fractionated crystallization of dispersed polyolefins in a polystyrene matrix. Macromol. Chem. Phys. 199:2275-2288

22. Arnal ML, Müller AJ (1999) Fractionated crystallisation of polyethylene and ethylene/a-olefin copolymers dispersed in immiscible polystyrene matrices. Macromol. Chem. Phys. 200:2559-2576

23. Schick C, Androsch R, Schmelzer JWP (2017) Homogeneous crystal nucleation in polymers. J. Phys.: Condens. Matter 29:453002

24. Santana OO. Müller AJ (1994) Homogeneous nucleation of the dispersed crystallizable component of immiscible polymer blends. Polym. Bull.32:471-477

25. Michell RM, Blaszczyk-Lezak I, Mijangos C, Müller AJ (2013) Confinement effects on polymer crystallization: From droplets to alumina nanopores. Polymer 54:40594077

26. Tol RT, Mathot VBF, Groeninckx G (2005) Confined crystallization phenomena in immiscible polymer blends with dispersed micro- and nanometer sized PA6 droplets, part 2: reactively compatibilized PS/PA6 and (PPE/PS)/PA6 blends. Polymer 46:383396

27. Tol RT, Mathot VBF, Groeninckx G (2005) Confined crystallization phenomena in immiscible polymer blends with dispersed micro- and nanometer sized PA6 droplets, part 3: crystallization kinetics and crystallinity of micro- and nanometer sized PA6 droplets crystallizing at high supercoolings. Polymer 46:2955-2965 
28. Yordanov C, Minkova L (2005) Fractionated crystallization of compatibilized LDPE/PA6 blends. Eur. Polym. J. 41:527-534

29. Anstey A, Codou A, Misra M, Mohanty AK (2018) Novel Compatibilized NylonBased Ternary Blends with Polypropylene and Poly(lactic acid): Fractionated Crystallization Phenomena and Mechanical Performance. ACS Omega 3:2845-2854

30. Huo H, Guo C, Zhou J, Zhao X (2014) The combination of fluctuation-assisted crystallization and interface-assisted crystallization in a crystalline/crystalline blend of poly(ethylene oxide) and poly(e-caprolactone). Colloid Polym. Sci. 292:971-983

31. Qiaolian Lv, Wu D, Xie H, Peng S, Chen Y, Xu C (2016) Crystallization of poly(3caprolactone) in its immiscible blend with polylactide: insight into the role of annealing histories. RSC Adv. 6:37721

32. Sakai F, Nishikawa K, Inoue Y, Yazawa K (2009) Nucleation Enhancement Effect in Poly(L-lactide) (PLLA)/Poly( $\varepsilon$-caprolactone) (PCL) Blend Induced by Locally Activated Chain Mobility Resulting from Limited Miscibility. Macromolecules $42: 8335-8342$

33. Pan P, Shan G, Bao Y (2014) Enhanced Nucleation and Crystallization of Poly(L-lactic acid) by Immiscible Blending with Poly(vinylidene fluoride). Ind. Eng. Chem. Res. 53:3148-3156

34. Kong Y, Ma Y, Lei L, Wang X, Wang H (2017) Crystallization of Poly( $\epsilon-$ caprolactone) in Poly(vinylidene fluoride)/Poly( $\varepsilon$-caprolactone) Blend. Polymers 9:42

35. Shi W, Chen F, Zhang Y, Han CC (2012) Viscoelastic Phase Separation and Interface Assisted Crystallization in a Highly Immiscible iPP/PMMA Blend. ACS Macro Lett. $1: 1086-1089$

36. Wu D, Lin D, Zhang J, Zhou W, Zhang M, Zhang Y, Wang D, Lin B (2011) Selective Localization of Nanofillers: Effect on Morphology and Crystallization of PLA/PCL Blends. Macromol. Chem. Phys. 212:613-626

37. Yu C, Han L, Bao J, Shan G, Bao Y, Pan P (2016) Polymorphic Crystallization and Crystalline Reorganization of Poly(L-lactic acid)/Poly(D-lactic acid) Racemic Mixture Influenced by Blending with Poly(vinylidene fluoride). J. Phys. Chem. B $120(32): 8046-8054$

38. Rizzuto M, Mugica A, Zubitur M, Caretti D, Müller AJ (2016) Plasticization and antiplasticization effects caused by poly(L-lactide-ran-caprolactone) addition to double crystalline poly(L-lactide)/poly( $\varepsilon$ - caprolactone) blends. CrystEngComm 18:2014 
39. Wei Q, Chionna D, Pracella M (2005) Reactive Compatibilization of PA6/LDPE Blends with Glycidyl Methacrylate Functionalized Polyolefins. Macromol. Chem. Phys. 206:777-786

40. Garcia-Garcia D, Rayon E, Carbonell-Verdu A, Lopez-Martinez J, Balart R (2017) Improvement of the compatibility between poly(3-hydroxybutyrate) and poly(ecaprolactone) by reactive extrusion with dicumyl peroxide. Eur. Polym. J. 86:41-57

41. Wang R, Wang S, Zhang Y, Wan C, Ma P (209) Toughening Modification of PLLA/PBS Blends via In Situ Compatibilization. Polym. Eng. Sci. 49:26-33

42. Liu NC, Xie HQ, Baker WE (1993) Comparison of the effectiveness of different basic functional groups for the reactive compatibilization of polymer blends. Polymer $34: 4680-4687$

43. Tri PN, Domenek S, Guinault A, Sollogoub C (2013) Crystallization Behavior of Poly(lactide)/Poly( $\beta$-hydroxybutyrate)/Talc Composites. J. Appl. Polym. Sci. $129: 3355-3365$

44. Jain S, Reddy MM, Mohanty AK, Misra M, Ghosh AK (2010) A New Biodegradable Flexible Composite Sheet from Poly(lactic acid)/Poly(e-caprolactone) Blends and Micro-Talc. Macromol. Mater. Eng. 295:750-762

45. Fenni SE, Monticelli O, Conzatti L, Doufnoune R, Stagnaro P, Haddaoui N, Cavallo D (2018) Correlating the morphology of poly(L-lactide)/poly(butylene succinate)/graphene oxide blends nanocomposites with their crystallization behavior. eXPRESS Polym. Lett. 12:58-70

46. Müller AJ, Avila M, Saenz G, Salazar J (2014) Crystallization of PLA-based Materials. In Jiménez A, Peltzer M, Ruseckaite R (eds) Poly(lactic acid) Science and Technology: Processing, Properties, Additives and Applications. The Royal Society of Chemistry, Cambridge, UK, p 66-98

47. Di Lorenzo MR, Androsch R (2015) Crystallization of Poly(lactic acid). In: Fakirov $S$ (ed) Biodegradable Polyesters. Wiley-VCH Verlag GmbH \& Co. KGaA, Weinheim, Germany, p 109-130

48. Androsch R, Schick C, Di Lorenzo ML (2017) Kinetics of Nucleation and Growth of Crystals of Poly(l-lactic acid). In: Advances in Polymer Science 279. Springer International, Basel, Switzerland, p - 235-272

49. Yokohara T, Yamaguchi M (2008) Structure and properties for biomass-based polyester blends of PLA and PBS. Eur. Polym. J. 44, 677-685 
50. Supthanyakul R, Kaabbuathong N, Chirachanchai S (2016) Random poly(butylene succinate-co-lactic acid) as a multi-functional additive for miscibility, toughness, and clarity of PLA/PBS blends. Polymer 105:1-9

51. Shibata M, Inoue Y, Miyoshi M (2006) Mechanical properties, morphology, and crystallization behavior of blends of poly(L-lactide) with poly(butylene succinate-coL-lactate) and poly(butylene succinate). Polymer 47:3557-3564

52. Wu D, Yuan L, Laredo E, Zhang M, Zhou W (202) Interfacial Properties, Viscoelasticity, and Thermal Behaviors of Poly(butylene succinate)/Polylactide Blend. Ind. Eng.Chem. Res. 51:2290-2298

53. Persenaire O, Quintana R, Lemmouchi Y, Sampson J, Martin S, Bonnaud L, Dubois P (2014) Reactive compatibilization of poly(L-lactide)/poly(butylene succinate) blends through polyester maleation: from materials to properties. Polym. Int. 63:1724-1731

54. Buasri A, Buranasing G, Piemjaiswang R, Yousatit S, Loryuenyong V (2014) Effect of titanium dioxide nanoparticles on mechanical and thermal properties of poly(lactic acid) and poly(butylene succinate) blends. Adv. Sci. Tech. 96:33-38

55. Zhang Z, Zhang Y (2016) Reinforcement effect of poly(butylene succinate) (PBS)grafted cellulose nanocrystal on toughened PBS/polylactic acid blends. Carbohydr. Polym. 140:374-382

56. Harada M, Ohya T, Iida K, Hayashi H, Hirano K, Fukuda H (2007) Increased Impact Strength of Biodegradable Poly(lactic acid)/Poly(butylene succinate) blend Composites by using Isocyanate as a Reactive Processing Agent. J. Appl. Polym. Sci.106:1813-1820

57. Hassan E, Wei Y, Jiao H, Muhuo Y (2013) Dynamic Mechanical Properties and Thermal Stability of Poly(lactic acid) and Poly(butylene succinate) Blends Composites. J. Fiber Bioeng. Inf. 6:85-94

58. Luzi F, Fortunati E, Jiménez A, Pugliaa D, Pezzolla D, Gigliotti G, Kenny JM, Chiralt A, Torre L (2016) Production and characterization of PLA PBS biodegradable blends reinforced with cellulose nanocrystals extracted from hemp fibres. Ind. Crops Prod. 93:276-289

59. Dell'Erba R, Maglio G, Malinconico M, Migliozzi A (2001) Immiscible polymer blends of semicrystalline biocompatible components: thermal properties and phase morphology analysis of PLLA/PCL blends. Polymer 42:7831-7840 
60. Shen T, Lu M, Liang L (2013) Modification of the Properties of Polylactide/ Polycaprolactone Blends by Incorporation of Blocked Polyisocyanate. J. Macromol. Sci. Part A Pure Appl. Chem. 50:547-554

61. Monticelli O, Calabrese M, Gardella L, Fina A, Gioffredi E (2014) Silsesquioxanes: Novel compatibilizing agents for tuning the microstructure and properties of PLA/PCL immiscible blends. Eur. Polym. J. 58:69-78

62. Mofokeng JP, Luyt AS (2015) Dynamic mechanical properties of PLA/PHBV, PLA/PCL, PHBV/PCL blends and their nanocomposites with $\mathrm{TiO} 2$ as nanofiller. Thermochim Acta 613:41-53

63. Lopez-Rodriguez N, Lopez-Arraiza A, Meaurio E, Sarasua JR (2006) Crystallization, Morphology, and Mechanical Behavior of Polylactide/Poly(-caprolactone) Blends. Polym. Eng. Sci. 46:1299-1308

64. Navarro-Baena I, Sessini V, Dominici F, Torre L, Kenny JM, Peponi L (2016) Design of biodegradable blends based on PLA and PCL: From morphological, thermal and mechanical studies to shape memory behavior. Polym. Degrad. Stab. 132:97-108

65. Han W, Liao X, He B, Yang Q, Li G (2018) Disclosing the crystallization behavior and morphology of poly( $\varepsilon$-caprolactone)/within poly( $\varepsilon$-caprolactone)/poly(L-lactide) blends. Polym. Int. 67:566-576

66. Derakhshandeh M, Noroozi N, Schafer LL, Vlassopoulos D, Hatzikiriakos SG (2016) Dynamics of partially miscible polylactide-poly( $\varepsilon$-caprolactone) blends in the presence of cold crystallization. Rheol. Acta 55:657-671

67. Cabedo L, Feijoo JL, Villanueva MP, Lagaron JM, Gimenez E (2006) Optimization of Biodegradable Nanocomposites Based on a PLA/PCL Blends for Food Packaging Applications. Macromol. Symp. 233:191-197

68. Bouakaz BS, Habi A, Grohens Y, Pillin I (2017) Organomontmorillonite/graphenePLA/PCL nanofilled blends: New strategy to enhance the functional properties of PLA/PCL blend. Appl. Clay Sci. 139:81-91

69. Harada M, Iida K, Okamoto K, Hayashi H, Hirano K (2008) Reactive Compatibilization of Biodegradable Poly(lactic acid)/Poly( $\varepsilon$-caprolactone) Blends with Reactive Processing Agents. Polym. Eng. Sci. $\underline{48}$ :1359-1368

70. Urquijo J, Guerrica-Echevarria G, Eguiazabal JI (2015) Melt processed PLA/PCL blends: Effect of processing method on phase structure, morphology, and mechanical properties. J. Appl. Polym. Sci. 42641:1-9 
71. Ostafinska A, Fortelny I, Nevoralova M, Hodan J, Kredatusova J, Slouf M (2015) Synergistic effects in mechanical properties of PLA/PCL blends with optimized composition, processing, and morphology. RSC Adv. 5, 98971

72. Bai H, Huang C, Xiu H, Gao Y, Zhang Q, Fu Q (2013) Toughening of poly(L-lactide) with poly( $\varepsilon$-caprolactone): Combined effects of matrix crystallization and impact modifier particle size. Polymer 54:5257-5266

73. Bai H, Xiu H, Gao J, Deng H, Zhang Q, Yang M, Fu Q (2012) Tailoring Impact Toughness of Poly(L-lactide)/Poly( $\varepsilon$-caprolactone) (PLLA/PCL) Blends by Controlling Crystallization of PLLA Matrix. ACS Appl. Mater. Interfaces 4:897-905

74. Na YH, He Y, Shuai X, Kikkawa Y, Doi Y, Inoue Y (2002) Compatibilization Effect of Poly(E-caprolactone)-b-poly(ethylene glycol) Block Copolymers and Phase Morphology Analysis in Immiscible Poly(lactide)/Poly( $\varepsilon$-caprolactone) Blends. Biomacromolecules 3:1179-1186

75. Wachirahuttapong S, Thongpin C, Sombatsompop N (2016) Effect of PCL and compatibility contents on the morphology, crystallization and mechanical properties of PLA/PCL blends. Energy Procedia 89:198-206

76. Chavalitpanya k, Phattanarudee S (2013) Poly(lactic acid)/Polycaprolactone Blends Compatibilized with Block Copolymer. Energy Procedia 34:542-548

77. Matta AK, Rao RU, Sumana KNS, Rambabuc V (2014) Preparation and Characterization of Biodegradable PLA/PCL Polymeric Blends. Procedia Mater. Sci. 6:1266-

78. Tuba F, Olah L, Nagy P (2011) Characterization of reactively compatibilized poly(D,L-lactide)/poly( $\varepsilon$-caprolactone) biodegradable blends by essential work of fracture method. Eng. Fract. Mech. 78:3123-3133

79. Androsch R, Di Lorenzo MR (2013) Kinetics of crystal nucleation of poly(L-lactic acid). Polymer 54:6882-6885

80. Di Lorenzo ML, Androsch R (2013) Crystal Nucleation in Glassy Poly(L-lactic acid). Macromolecules 46, 6048-6056

81. Liu Q, Zhou XM (2015) Preparation of Poly(butylene succinate)/poly( $\epsilon$-caprolactone) Blends Compatibilized With Poly(butylene succinate-co-€-caprolactone) Copolymer. J. Macromol. Sci. Part A Pure Appl. Chem. 52:625-629

82. Qiu Z, Komura M, Ikehara T, Nishi T (2003) Miscibility and crystallization behavior of biodegradable blends of two aliphatic polyesters. Poly(butylene succinate) and Poly(1-caprolactone). Polymer 44:7749-7756 
83. Gumede TP, Luyt AS, Müller AJ (2018) Review on PCL, PBS, and PCL/PBS blends containing carbon nanotubes. eXPRESS Polym. Lett. 12:505-529

84. Zhang J, Sato H, Furukawa T, Tsuji H, Noda I, Ozaki Y (2006) Crystallization Behaviors of Poly(3-hydroxybutyrate) and Poly(L-lactic acid) in Their Immiscible and Miscible Blends. J. Phys. Chem. B 110:24463-24471

85. Sato H, Nakamura M, Padermshoke A, Yamaguchi H, Terauchi H, Ekgasit S, Noda I, Ozaki Y (2004) Thermal Behavior and Molecular Interaction of Poly(3hydroxybutyrate-co-3-hydroxyhexanoate) Studied by Wide-Angle X-ray Diffraction. Macromolecules 37:3763-3769

86. Sato H, Murakami R, Padermshoke A, Hirose F, Senda K, Noda I, Ozaki Y (2004) Infrared Spectroscopy Studies of $\mathrm{CH}^{\cdots} \mathrm{O}$ Hydrogen Bondings and Thermal Behavior of Biodegradable Poly(hydroxyalkanoate). Macromolecules 37:7203-7213

87. Zhang L, Xiong C, Deng X (1996) Miscibility, crystallization and morphology of poly(P-hydroxybutyrate)/ poly(d,1-lactide) blends. Polymer 37:235-241

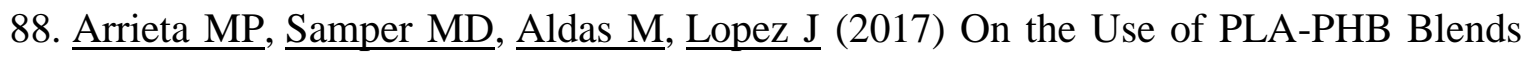
for Sustainable Food Packaging Applications. Materials 10, 1008

89. Arrieta MP, Lopez J, Rayon E, Jimenez A (2014) Disintegrability under composting conditions of plasticized PLA-PHB blends. Polym. Degrad. Stab. 108:307-318

90. Armentano I, Fortunati E, Burgos N, Dominici F, Luzi F, Fiori S, Jimenez A, Yoon K, Ahn J, Kang S, Kenny JM (2015) Processing and characterization of plasticized PLA/PHB blends for biodegradable multiphase systems. eXPRESS Polym. Lett. 9:583-596

91. Zhang M, Thomas NL (2011) Blending Polylactic Acid with Polyhydroxybutyrate: The Effect on Thermal, Mechanical, and Biodegradation Properties. Advances in Polymer Technology 30:67-79

92. Arrieta MP, Fortunati E, Dominici F, Lopez J, Kenny JM (2015) Bionanocomposite films based on plasticized PLA-PHB/cellulose nanocrystal blends. Carbohydr. Polym. $121: 265-275$

93. Arrieta MP, Fortunati E, Dominici F, Rayon E, Lopez J, Kenny JM (2014) Multifunctional PLA-PHB/cellulose nanocrystal films: Processing, structural and thermal properties. Carbohydr. Polym. 107:16-24

94. Arrieta MP, Castro-Lopez MDM, Rayon E, Barral-Losada LF, Lopez-Vilarino JM, Lopez J, Gonzalez-Rodriguez MV (2014) Plasticized Poly(lactic acid)-Poly(hydroxybutyrate) (PLA-PHB) Blends Incorporated with Catechin 
Intended for Active Food-Packaging Applications. J. Agric. Food Chem. 62:1017010180

95. Arrieta MP, Lopez J, Hernandez A, Rayon E (2014) Ternary PLA-PHB-Limonene blends intended for biodegradable food packaging applications. Eur. Polym. J. 50:255270

96. Abdelwahab MA, Flynn A, Chiou BS, Imam S, Orts W, Chiellini E (2012) Thermal, mechanical and morphological characterization of plasticized PLA-PHB blends. Polym. Degrad. Stab. 97:1822-1828

97. Blumm E, Owen AJ (195) Miscibility, crystallization and melting of poly(3hydroxybutyrate)/poly( L-lactide) blends. Polymer 36:4077-4081

98. Xu J, Bao J, Guo BH, Ma H, Yun TL, Gao L, Chen GQ, Iwata T (2007) Imaging of nonlinear optical response in biopolyesters via second harmonic generation microscopy and its dependence on the crystalline structures. Polymer 48:348-355

99. Ohkoshia I, Abe H, Y, Doi Y (2000) Miscibility and solid-state structures for blends of poly[(S)-lactide] with atactic poly[(R,S)-3-hydroxybutyrate]. Polymer 41:59855992

100. Schultz JM (ed) (2001) Polymer Crystallization: The Development of Crystalline Order in Thermoplastic Polymers. American Chemical Society, New York 101. Ma P, Hristova-Bogaerds DG, Zhang Y, Lemstra PJ (2014) Enhancement in crystallization kinetics of the bacterially synthesized poly( $\beta$-hydroxybutyrate) by poly(butylene succinate). Polym. Bull. 71:907-923

102. Qiu Z, Ikehara T, Nishi T (2003) Poly(hydroxybutyrate)/poly(butylene succinate) blends: miscibility and nonisothermal crystallization. Polymer 44:25032508

103. Lovera D, Marquez L, Balsamo V, Taddei A, Castelli C, Müller AJ (2007) Crystallization, Morphology, and Enzymatic Degradation of Polyhydroxybutyrate / Polycaprolactone (PHB/PCL) Blends. Macromol. Chem. Phys. 208:924-937 